ARTICLE

\title{
Subnanometric alkaline-earth oxide clusters for sustainable nitrate to ammonia photosynthesis
}

\author{
Jieyuan $\mathrm{Li}^{1,2}$, Ruimin Chen ${ }^{1}$, Jielin Wang ${ }^{1}$, Ying Zhou (D) ${ }^{3}$, Guidong Yang ${ }^{4} \&$ Fan Dong (D) ${ }^{1,2}{ }^{凶}$
}

The limitation of inert $\mathrm{N}_{2}$ molecules with their high dissociation energy has ignited research interests in probing other nitrogen-containing species for ammonia synthesis. Nitrate ions, as an alternative feedstock with high solubility and proton affinity, can be facilely dissociated for sustainable ammonia production. Here we report a nitrate to ammonia photosynthesis route $\left(\mathrm{NO}_{3}-\mathrm{RR}\right)$ catalyzed by subnanometric alkaline-earth oxide clusters. The catalyst exhibits a high ammonia photosynthesis rate of $11.97 \mathrm{~mol} \mathrm{~g}_{\text {metal }}{ }^{-1} \mathrm{~h}^{-1}\left(89.79 \mathrm{mmol} \mathrm{g}_{\text {cat }}{ }^{-1} \mathrm{~h}^{-1}\right)$ with nearly $100 \%$ selectivity. A total ammonia yield of $0.78 \mathrm{mmol}$ within $72 \mathrm{~h}$ is achieved, which exhibits a significant advantage in the area of photocatalytic $\mathrm{NO}_{3}-\mathrm{RR}$. The investigation of the molecular-level reaction mechanism reveals that the unique active interface between the subnanometric clusters and $\mathrm{TiO}_{2}$ substrate is beneficial for the nitrate activation and dissociation, contributing to efficient and selective nitrate reduction for ammonia production with low energy input. The practical application of $\mathrm{NO}_{3}-\mathrm{RR}$ route in simulated wastewater is developed, which demonstrates great potential for its industrial application. These findings are of general knowledge for the functional development of clusters-based catalysts and could open up a path in the exploitation of advanced ammonia synthesis routes with low energy consumption and carbon emission.

\footnotetext{
${ }^{1}$ Research Center for Environmental and Energy Catalysis, Institute of Fundamental and Frontier Sciences, University of Electronic Science and Technology of China, Chengdu 611731, China. ${ }^{2}$ Yangtze Delta Region Institute (Huzhou), University of Electronic Science and Technology of China, Huzhou 313000, China. ${ }^{3}$ School of New Energy and Materials, Southwest Petroleum University, Chengdu 610500, China. ${ }^{4}$ XJTU-Oxford Joint International Research Laboratory of

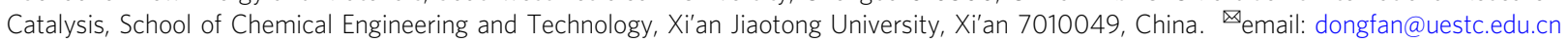


$s$ an essential chemical, ammonia $\left(\mathrm{NH}_{3}\right)$ is industrially produced via the Haber-Bosch process, which consumes $1.0-2.0 \%$ of the world's energy output and contributes to $1.6 \%$ of the world's carbon emissions ${ }^{1-4}$. As an alternative, artificial electro-/photo-/photoelectrochemical nitrogen reduction reactions $\left(\mathrm{N}_{2} \mathrm{RRs}\right)$ for $\mathrm{NH}_{3}$ synthesis, inspired by the natural microbial $\mathrm{N}_{2}$ fixation, have attracted tremendous research interest ${ }^{5,6}$. Despite great achievements in recent decades, it is inconvenient to overlook that the future of $\mathrm{N}_{2} \mathrm{RRs}$ is plagued by the ultrahigh dissociation energy of the $\mathrm{N} \equiv \mathrm{N}$ bond $\left(941 \mathrm{~kJ} \mathrm{~mol}^{-1}\right)^{7,8}$. Inferior catalytic performance is predictable, arising from the limited solubility and low proton affinity of the inert $\mathrm{N}_{2}$.

From an energy viewpoint, nitrate ions $\left(\mathrm{NO}_{3}{ }^{-}\right)$, as a sustainable $\mathrm{N}$-containing alternative, can be disintegrated at lower dissociation energy of $204 \mathrm{~kJ} \mathrm{~mol}^{-1}$, contributing to an accelerated reaction kinetics for $\mathrm{NH}_{3}$ synthesis ${ }^{9-13}$. Besides, the highest valence state of $\mathrm{N}$-element in $\mathrm{NO}_{3}^{-}$ensures that the deep reduction reaction can be achieved for selective $\mathrm{NH}_{4}{ }^{+}$synthesis. The intermediate-valence $\mathrm{N}_{2}$ oxidation and reduction may proceed simultaneously when conducting $\mathrm{N}_{2} \mathrm{RR}$, which restrains the $\mathrm{NH}_{4}{ }^{+}$selectivity ${ }^{14-16}$. Another virtue of using $\mathrm{NO}_{3}{ }^{-}$feedstock lies in its rich distribution in wastewater. The abundant nitrate in wastewater offers sufficient reactants for $\mathrm{NO}_{3}{ }^{-}$reduction reaction $\left(\mathrm{NO}_{3}-\mathrm{RR}\right)$ routes ${ }^{17-20}$. Instead of the partial reduction of $\mathrm{NO}_{3}{ }^{-}$ to $\mathrm{N}_{2}$ for its purification, the eight-electron transfer reaction for $\mathrm{NO}_{3}{ }^{-}$to $\mathrm{NH}_{4}{ }^{+}$synthesis provides an opportunity for the valueadded conversion of contaminative $\mathrm{NO}_{3}{ }^{-}$into ammonia as an economically competitive product. Also, the wide distribution of general organic matters such as aldehydes and phenols in wastewater is noted, which forms contaminant mixtures with nitrate $^{21}$. These organic matters can serve as the hole sacrificial agents, which accelerates both the $\mathrm{NO}_{3}{ }^{-}$reduction for $\mathrm{NH}_{4}{ }^{+}$ synthesis and pollutants' oxidation for their degradation. Thus, the development of a $\mathrm{NO}_{3}{ }^{-} \mathrm{RR}$ route for $\mathrm{NH}_{4}{ }^{+}$production, which provides sustainable $\mathrm{N}$-cycle utilization, has a profound effect in both reducing energy consumption and mitigating environmental anxieties.

Despite its advantages, $\mathrm{NO}_{3}{ }^{-} \mathrm{RR}$ also suffers from some inevitable difficulties as an active, yet challenging area of current research. In the eight-electron transfer reaction for $\mathrm{NO}_{3}{ }^{-}-\mathrm{NH}_{4}{ }^{+}$ synthesis, competitive side reactions may be fierce, mainly ascribed to five-electron transfer for the partial reduction of $\mathrm{NO}_{3}{ }^{-}$to $\mathrm{N}_{2}$ and hydrogen evolution reaction (HER) ${ }^{22-24}$. Moreover, it is well established that the yield rate and selectivity for $\mathrm{NH}_{4}{ }^{+}$dominantly rely on the development of novel catalytic materials, precise regulation of the reaction parameters and systematic investigation of the reaction mechanism. In this scenario, a comprehensive catalysis system requires a rational design to sufficiently promote catalytic performance.

As a typical solid-liquid heterogeneous catalytic reaction, the interaction between catalysts and solvents is essential in the $\mathrm{NO}_{3}{ }^{-} \mathrm{RR}$ system. Generally, metal cations $\left(\mathrm{M}^{\mathrm{x}+}\right)$ are introduced into solvents, serving as key functional components such as cocatalysts, ionic liquids or electrolytes ${ }^{25-27}$. With the catalytic reaction on stream, the dynamic evolution of $\mathrm{M}^{\mathrm{x}+}$ can be observed $^{28,29}$. With the assistance of appropriate catalyst support and reaction conditions, the deposition of $\mathrm{M}^{\mathrm{x}}+$ on a solid surface is expected, which leads to the production of corresponding single atoms, nanoclusters or nanoparticles on a substrate surface ${ }^{30-32}$, thereby modifying the interfacial structure and in situ serving as the catalytic active sites. Key challenge lies in revealing the interfacial structure of active sites for facilitating the ammonia selectivity and suppressing the occurrence of side reactions (HER and $\mathrm{NO}_{3}{ }^{-}$to $\mathrm{N}_{2}$ ) to enhance the efficiency.

Here, we demonstrate a general strategy to accomplish the operando construction of subnanometric alkaline-earth oxide clusters $\left(\mathrm{MO}_{\mathrm{NCs}}, \mathrm{M}=\mathrm{Mg}, \mathrm{Ca}, \mathrm{Sr}\right.$ or $\left.\mathrm{Ba}\right)$ as the active sites due to the nontoxicity and low price of alkaline-earth metals. Also, the widely investigated $\mathrm{TiO}_{2}$ nanosheets (TNS) is applied as the substrate since it is easy to be fabricated and characterized. After the operando construction of the $\mathrm{BaO}_{\mathrm{NCs}}$-TNS composite, a high ammonia photosynthesis rate of $11.97 \mathrm{molg}_{\text {metal }}{ }^{-1} \mathrm{~h}^{-1}$ $\left(89.79 \mathrm{mmol} \mathrm{g}_{\mathrm{cat}}{ }^{-1} \mathrm{~h}^{-1}\right)$ is reached with nearly $100 \%$ selectivity. A total ammonia yield of $0.78 \mathrm{mmol}$ within $72 \mathrm{~h}$ is achieved. The local interfacial structure is precisely tailored to strengthen charge transfer at the $\mathrm{MO}_{\mathrm{NCs}} / \mathrm{TNS}$ interface. Then, it is revealed that the eight-electron transfer reaction for $\mathrm{NO}_{3}{ }^{-} \mathrm{RR}$ is notably accelerated to achieve a high rate for sustainable $\mathrm{NH}_{4}{ }^{+}$photosynthesis. The practical application of $\mathrm{NO}_{3}{ }^{-} \mathrm{RR}$ route in simulated wastewater is also developed, which establishes an intriguing "sacrificial-agent-free" route for ammonia synthesis and demonstrates great potential for its real industrial application. The current ammonia photosynthesis route could provide an alternative route for nitrogen cycle utilization and promote the development of low-carbon technology.

\section{Results}

Operando construction of the subnanometric clusters. Alkaline-earth ions $(50 \mathrm{mg} / \mathrm{L})$ are first injected into the reaction mixture for the $\mathrm{NO}_{3}{ }^{-} \mathrm{RR}$ on TNS. Scanning electron microscopy (SEM), transmission electron microscopy (TEM) and X-ray diffraction (XRD) results demonstrate that the morphology and crystal structure of TNS is well maintained after alkaline-earth ion incorporation (Supplementary Figs. 1-3). To reveal the operando evolution of the alkaline-earth ions, the mixture is extracted from the reaction on stream. As identified by the quasi in situ high-angle annular dark-field scanning transmission electron microscopy (HAADF-STEM), the operando evolution of the alkaline-earth species on the catalyst surface is observed (Fig. 1).

Taking $\mathrm{Ba}^{2+}$ as an example, once the $\mathrm{BaCl}_{2} \cdot 2 \mathrm{H}_{2} \mathrm{O}$ is introduced into the reaction mixture, single atoms $\left(\mathrm{Ba}_{\mathrm{SAs}}\right)$ are constructed on the TNS surface after $5 \mathrm{~min}$ of irradiation (Fig. 1a). The subsequent growth and agglomeration of $\mathrm{Ba}_{\mathrm{SAs}}$ lead to the generation of subnanometric $\mathrm{BaO}$ clusters $\left(\mathrm{BaO}_{\mathrm{NCs}}\right)$ with a size of $\sim 0.6 \mathrm{~nm}$ (Fig. 1b). With prolonged irradiation time (Fig. 1c, $\mathrm{d}$ for 60 and 120 min respectively), uniformly dispersed $\mathrm{BaO}_{\mathrm{NCs}}$ with a mean size of $0.7 \pm 0.3 \mathrm{~nm}$ are formed on TNS. In addition, the HAADF-STEM elemental mappings (Fig. 1e) confirm that the $\mathrm{MO}_{\mathrm{NCs}}$ are mainly composed of Ba. It is worth noting that the variation of the $\mathrm{Ba}^{2+}$ concentration is revealed by ion chromatography (IC) detection (Fig. 1f). A continuous decrease in the $\mathrm{Ba}^{2+}$ concentration is observed within the first 60 min of irradiation. Then, equilibrium is reached to guarantee the subnanometric size of the $\mathrm{BaO}_{\mathrm{NCs}}$, thereby preventing excessive agglomeration and further growth. In addition, the operando construction of $\mathrm{MgO}_{\mathrm{NCs}}, \mathrm{CaO}_{\mathrm{NCs}}$ and $\mathrm{SrO}_{\mathrm{NCs}}$ is accomplished under the same procedure as that for the $\mathrm{BaO}_{\mathrm{NCs}}$ (Supplementary Figs. 4-8), indicating that this is a general strategy to form the $\mathrm{MO}_{\mathrm{NCs}}$.

Characterization and electronic properties of the $\mathrm{MO}_{\mathrm{NCs}}-\mathrm{TNS}$ composites. The chemical components and valence states of the $\mathrm{BaO}_{\mathrm{NCs}}$ were investigated by X-ray photoelectron spectroscopy (XPS, Fig. 2a and Supplementary Fig. 9). The deconvolution of the $\mathrm{Ba} 3 d$ XPS spectrum illustrates that the four characteristic peaks are fitted at the binding energies of 794.61, 792.84, 778.99, and $777.15 \mathrm{eV}$. The peaks located at 792.84 and $777.15 \mathrm{eV}$ correspond to the spin orbits of $\mathrm{Ba} 3 d_{3 / 2}$ and $\mathrm{Ba} 3 d_{5 / 2}$ respectively, demonstrating the generation of $\mathrm{BaO}_{\mathrm{NCs}}$ on the TNS surface. The other two shoulder peaks (794.61 and $778.99 \mathrm{eV}$ ) are identified as 

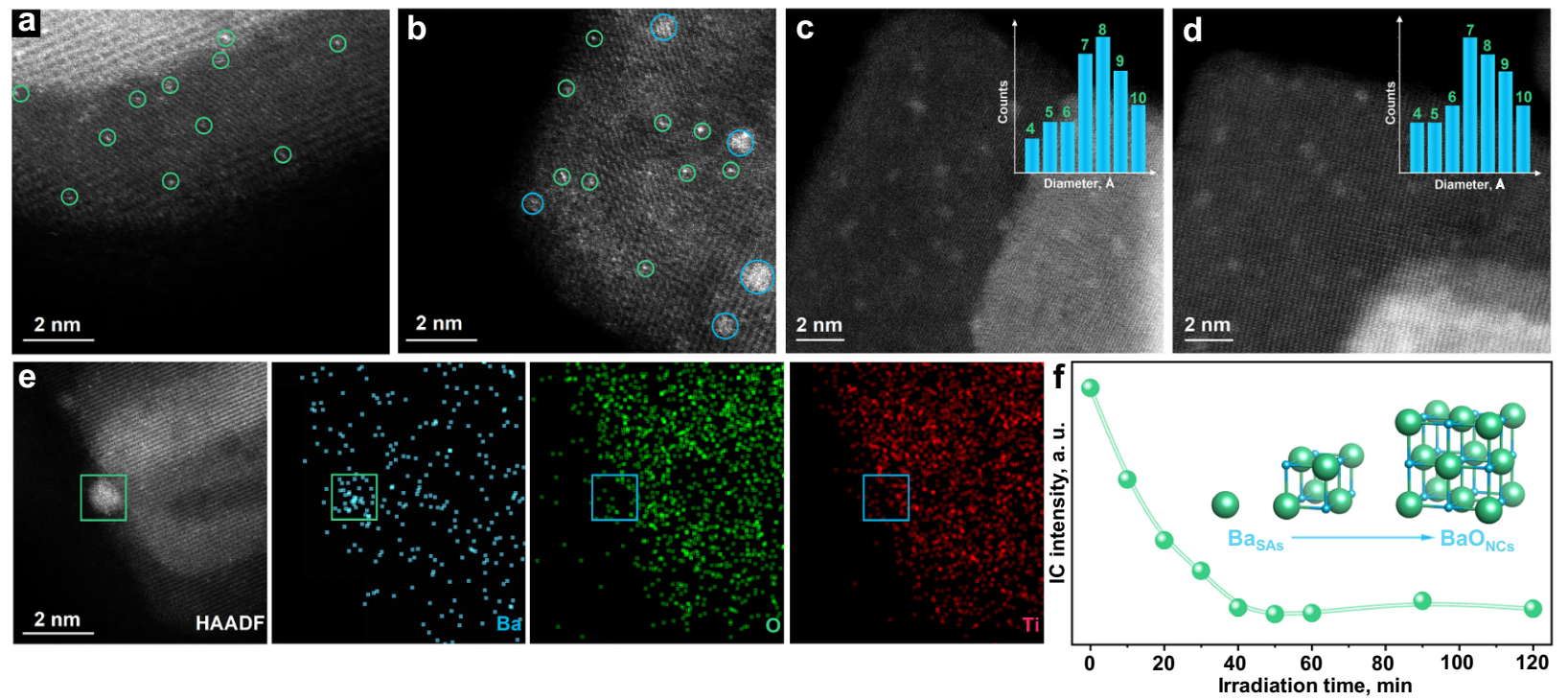

Fig. 1 Structure identification of subnanometric $\mathrm{BaO}$ nanoclusters $\left(\mathrm{BaO}_{\mathrm{NCs}}\right.$ ) operando construction on $\mathrm{TiO}_{\mathbf{2}}$ nanosheets (TNS) support. a-d Quasi in situ high-angle annular dark-field scanning transmission electron microscopy (HAADF-STEM) images showing the evolution course from isolated Ba single atoms $\left(\mathrm{Ba}_{\mathrm{SAs}}\right)$ to subnanometric $\left(\mathrm{BaO}_{\mathrm{NCs}}\right)$ at the irradiation time of $5 \mathrm{~min}(\mathbf{a}), 10 \mathrm{~min}(\mathbf{b}), 60 \mathrm{~min}(\mathbf{c})$ and 120 min (d) respectively. The related size distribution is labeled as insets (c, $\mathbf{d})$, in which the range of both $x$ (0.4-1.0) and $y(0-7)$ axes are set consistently. e, HAADF-STEM image (left) and respective elemental mapping images (right) verifying the component of $\mathrm{Ba}$ elements on the $\mathrm{BaO}_{\mathrm{NCs}}-\mathrm{TNS}$ surface. $\mathbf{f}$ Variation of $\mathrm{Ba}{ }^{2+}$ concentration during the operando construction of $\mathrm{BaO}_{\mathrm{NCs}}$ detected by ion chromatography.

$\mathrm{Ba}-\mathrm{O}$ bond formation between the $\mathrm{Ba}$ in the $\mathrm{BaO}_{\mathrm{NCs}}$ and the $\mathrm{O}$ in the $\mathrm{TNS}^{33,34}$. The concentration of $\mathrm{Ba}$ is determined to be $0.75 \mathrm{wt} . \%$ and 0.26 at.\% by using X-ray fluorescence (XRF) spectroscopy (Supplementary Fig. 10). To investigate the underlying growth pattern and mechanism of $\mathrm{BaO}_{\mathrm{NCs}}$, electron paramagnetic resonance (EPR) measurements were conducted for the pristine TNS before and after light irradiation (Fig. 2b and Supplementary Fig. 11). The intensified signal for lone-pair electrons after light irradiation discloses that the oxygen vacancies in TNS can be constructed via light irradiation, which agrees with the reported results ${ }^{35-37}$. Furthermore, it is confirmed by density function theory (DFT, Fig. 2c) calculations that the construction of $\mathrm{BaO}_{\mathrm{NCs}}$ at the defective site of TNS is more energy-favorable $(-0.69 \mathrm{eV})$ than that of pristine TNS $(-0.36 \mathrm{~V})$. A uniform pattern for the deposition of other alkaline-earth $\mathrm{MO}_{\mathrm{NCs}}$ on TNS is confirmed (Supplementary Figs. 12-15), which indicates that the subnanometric $\mathrm{MO}_{\mathrm{NCs}}$ can be precisely immobilized at the light-induced vacancy sites on TNS with this general method. Since the number of lone-pair electrons is limited at the vacancy sites, the cluster size is restricted at the subnanometric region, which hampers their excessive agglomeration and growth, thus achieving operando construction of subnanometric $\mathrm{MO}_{\mathrm{NCs}}$ at the defective sites of TNS.

Next, the optical and electronic properties of the as-prepared subnanometric $\mathrm{MO}_{\mathrm{NCs}}$-TNS composites were surveyed. Steady and time-resolved photoluminescence spectra (Fig. 2d and Supplementary Figs. 16 and 17) show that the charge separation capacity of TNS is observably enhanced after the operando construction of $\mathrm{MO}_{\mathrm{NCs}}$. The prolonged carriers' lifetime is beneficial for the participation of photoinduced electrons to catalyze the $\mathrm{NO}_{3}{ }^{-} \mathrm{NH}_{4}{ }^{+}$photosynthesis reaction. Besides, the red shift of the light absorption range (Fig. $2 \mathrm{~d}$ inset and Supplementary Fig. 18) implies that the light capture and utilization ability is facilitated via the deposition of $\mathrm{MO}_{\mathrm{NCs}}$. Then the Mott-Schottky spectra and UV-vis diffuse reflection spectra (DRS) were combined to determine the band structures of TNS and $\mathrm{BaO}_{\mathrm{NCs}}-\mathrm{TNS}$ (Supplementary Fig. 19). It is noted that the conduction band position of $\mathrm{BaO}_{\mathrm{NCs}}$-TNS is elevated than that of the pristine TNS, which could enhance the reduction capacity for the elevated $\mathrm{NO}_{3}{ }^{-} \mathrm{RR}$ performance. Molecular-level insights into the charge transfer patterns at $\mathrm{MO}_{\mathrm{NCs}} / \mathrm{TNS}$ interface were further revealed by DFT calculations (Fig. 2e and Supplementary Figs. 20-22). As supported by both standard Perdew-BurkeErnzerhof (PBE) functional and $\mathrm{PBE}+U$ correction calculations for the planar average potential energy profile, a distinct energy gap is generated between the $\mathrm{BaO}_{\mathrm{NCs}}$ and TNS surface, which facilitates directional electron migration from the $\mathrm{BaO}_{\mathrm{NCs}}$ to TNS. It is also confirmed by the charge difference distribution (Fig. 2e inset) that intense charge clouds accumulate at the $\mathrm{BaO}_{\mathrm{NCs}} / \mathrm{TNS}$ interface, building a unique electronic channel to promote charge transfer. Due to the superior photochemical properties contributed by the operando construction of the $\mathrm{MO}_{\mathrm{NCs}}-\mathrm{TNS}$ composite, the elevated catalytic performance of the $\mathrm{NO}_{3}{ }^{-} \mathrm{RR}$ for $\mathrm{NH}_{4}{ }^{+}$photosynthesis is expected.

$\mathrm{NO}_{3}{ }^{-}$to $\mathrm{NH}_{4}{ }^{+}$photosynthesis performance. The evaluation of the $\mathrm{NO}_{3}{ }^{-} \mathrm{RR}$ for $\mathrm{NH}_{4}{ }^{+}$photosynthesis was first conducted in $100 \mathrm{~mL}$ of $\mathrm{KNO}_{3}$ solution $\left(20 \mathrm{mg} / \mathrm{L}\right.$ of $\left.\mathrm{NO}_{3}{ }^{-}\right)$containing $5.0 \%$ ethylene glycol (EG) as the hole sacrificial agent under fullspectrum illumination. Briefly, $5.0 \mathrm{mg}$ of pristine TNS is applied as the catalyst support, in which $50.0 \mathrm{mg} / \mathrm{L}$ alkaline-earth ions are injected. As depicted in Fig. 3a, the pristine TNS exhibits nice catalytic activity $\left(1.65 \mathrm{mmol} \mathrm{g}_{\text {cat }}{ }^{-1} \mathrm{~h}^{-1}\right)$. The oxygen vacancies (OVs) in TNS are identified as the active sites due to the observable OVs construction via light irradiation (Fig. 2b and Supplementary Fig. 11). Most importantly, the operando construction of $\mathrm{MO}_{\mathrm{NCs}}$ (illustrated in Fig. 1f) and enhancement of the $\mathrm{NH}_{4}{ }^{+}$ photosynthesis rate are simultaneously accomplished with the reaction on stream. Since the construction of $\mathrm{MO}_{\mathrm{NCs}}$ and $\mathrm{NH}_{4}{ }^{+}$ synthesis proceed at the same time, the $\mathrm{NH}_{4}{ }^{+}$synthesis rate by $\mathrm{MO}_{\mathrm{NCs}}$ is elevated and the gradual increase of the slope for $\mathrm{NH}_{4}{ }^{+}$ generation is reasonable. The $\mathrm{NH}_{4}^{+}$synthesis rate is increased from $1.65 \mathrm{mmol} \mathrm{g}_{\mathrm{cat}}{ }^{-1} \mathrm{~h}^{-1}$ with pristine TNS to $3.78 \mathrm{mmol}$ $\mathrm{g}_{\mathrm{cat}}{ }^{-1} \mathrm{~h}^{-1}$ with $\mathrm{BaO}_{\mathrm{NCs}}-\mathrm{TNS}$, which demonstrates the significant advantage of subnanometric $\mathrm{MO}_{\mathrm{NCs}}$ as cocatalyst. The apparent quantum efficiency (Supplementary Note 1) for these as-prepared 

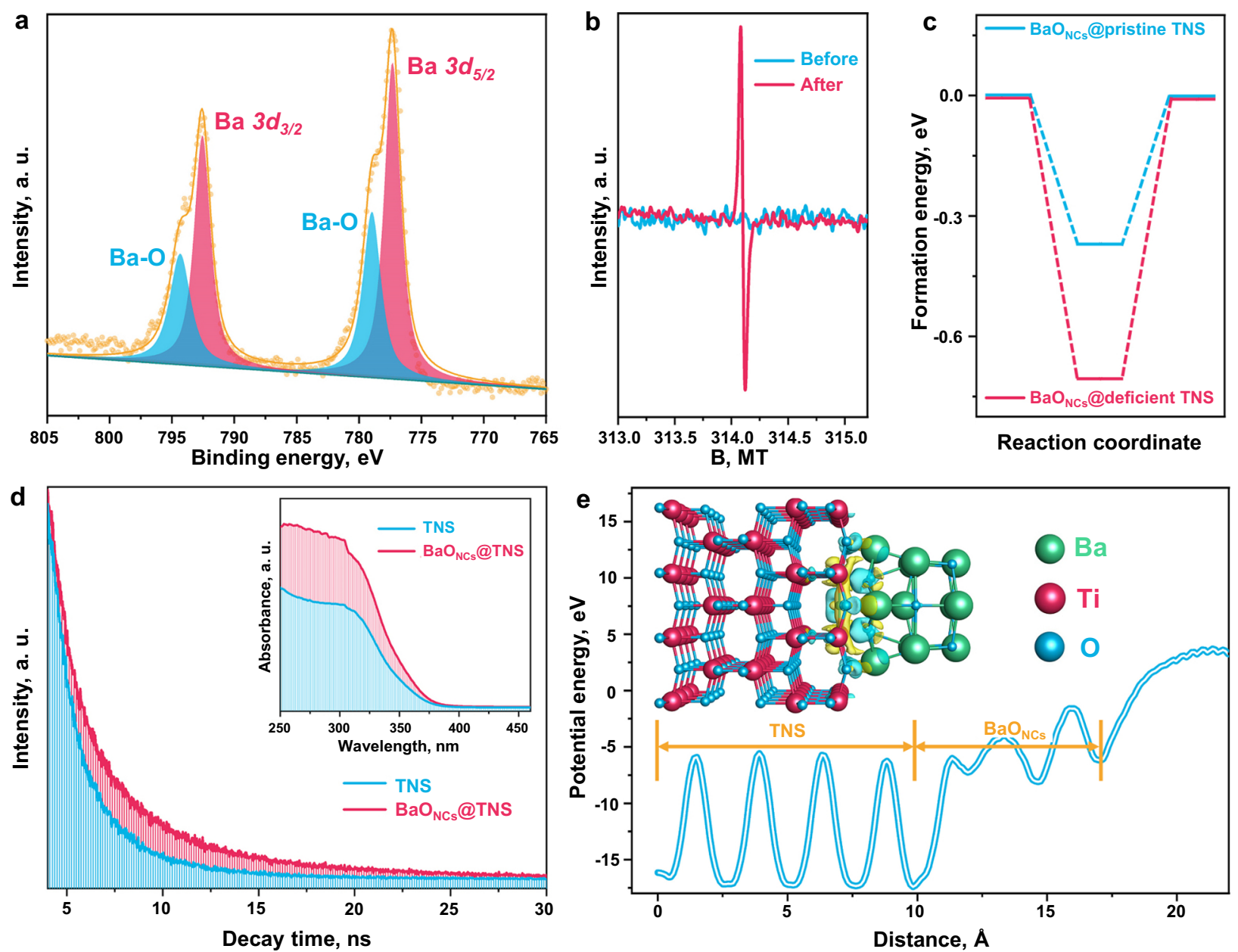

Fig. 2 Chemical composition and electronic structure. a Ba $3 d$ X-ray photoelectron spectroscopy (XPS) spectra of BaO $\mathrm{NCs}^{-T N S . ~ b ~ R o o m ~ t e m p e r a t u r e ~ s o l i d ~}$ electron paramagnetic resonance (EPR) results of TNS before and after irradiation for 30 min. c Calculated binding energy of $\mathrm{BaO}_{\mathrm{NCs}}$ deposited at pristine and deficient TNS surfaces respectively. d Time-resolved fluorescence emission decay spectra. Inset: UV-vis diffuse reflection spectra (DRS) results. e Calculated planer average potential energy profile using Perdew-Burke-Ernzerhof (PBE) $+U$ correction. Inset: calculated charge difference distribution at the $\mathrm{BaO}_{\mathrm{NCS}}$ /TNS interface, in which charge accumulation is marked in blue and charge depletion is marked in yellow. The isosurfaces were set to $0.005 \mathrm{eV} \AA^{-3}$

samples is also enhanced in the order of TNS $(1.86 \%)<\mathrm{CaO}_{\mathrm{NCs}^{-}}$ TNS $(2.59 \%)<\mathrm{MgO}_{\mathrm{NCs}}$-TNS $(3.09 \%)<\mathrm{SrO}_{\mathrm{NCs}}-\mathrm{TNS}(3.22 \%)<$ $\mathrm{BaO}_{\mathrm{NCs}}-\mathrm{TNS}(3.46 \%)$. In addition, the controlled experiment is conducted by adding $\mathrm{KCl}$ into the catalysis system of pristine TNS without other cations or anions (Supplementary Fig. 23), which excludes the potential involvement of $\mathrm{Cl}^{-}$from the source of alkaline earth source $\left(\mathrm{MCl}_{2} \cdot \mathrm{xH}_{2} \mathrm{O}\right)$. It is observed that the $\mathrm{NO}_{3}-\mathrm{RR}$ to ammonia efficiency is not promoted by the addition of $\mathrm{Cl}^{-}$, which identifies that the enhanced activity is contributed by the construction of $\mathrm{MO}_{\mathrm{NCs}}-\mathrm{TNS}$. Since the operando production of $\mathrm{MO}_{\mathrm{NCs}}$ on TNS is preferable to achieve at the OVs sites (Fig. 2c and Supplementary Figs. 12-15), the active sites in $\mathrm{MO}_{\mathrm{NCs}}-\mathrm{TNS}$ are regarded as the $\mathrm{MO}_{\mathrm{NCs}} @ \mathrm{OV}$ s interfaces. Besides, to further unveil the activity origin of $\mathrm{MO}_{\mathrm{NCs}}-\mathrm{TNS}$, we conduct an additional control experiment by replacing the TNS substrate with inert $\mathrm{SiO}_{2}$ nanoparticles (Supplementary Fig. 24). It is observed that no $\mathrm{NH}_{4}{ }^{+}$can be detected during the simultaneous construction of $\mathrm{MO}_{\mathrm{NCs}}-\mathrm{SiO}_{2}$ and $\mathrm{NO}_{3}-\mathrm{RR}$. Hence, it is clarified that the enhanced $\mathrm{NH}_{4}{ }^{+}$synthesis efficiency gives credit to the construction of $\mathrm{MO}_{\mathrm{NCs}}$-TNS composites.

Because the catalytic efficiency is directly related to reaction parameters, the reaction parameters are comprehensively optimized to further promote catalytic performance (Fig. 3b), including the $\mathrm{NO}_{3}{ }^{-}$concentration, catalyst dose, and light source. It is observed that the increase in $\mathrm{NO}_{3}^{-}$concentration $(100.0 \mathrm{mg} / \mathrm{L})$ is beneficial for accelerating the reaction kinetics of $\mathrm{NO}_{3}{ }^{-} \mathrm{RR}$ (Supplementary Fig. 25). The saddle point of the catalyst dose is located at $1.0 \mathrm{mg}$ to accomplish the optimal unit activity (Supplementary Fig. 26). Besides, since $\mathrm{NO}_{3}{ }^{-}$could be preactivated by UV light, which tailors the coordination environment of the stable $\mathrm{NO}_{3}^{-}$and drives it into some active intermediates such as monodentate $\mathrm{NO}_{3}{ }^{-},-\mathrm{NO}_{2}$ and $\mathrm{NO}_{2}{ }^{-}$ (Supplementary Fig. 27), the utilization of different light sources was tested. Notably, the optimal $\mathrm{NH}_{4}{ }^{+}$photosynthesis rate is $38.00 \mathrm{mmol} \mathrm{g}_{\mathrm{cat}}{ }^{-1} \mathrm{~h}^{-1}$ with pristine TNS after regulating the reaction parameters (Supplementary Fig. 28). Moreover, an accelerated rate for $\mathrm{NH}_{4}^{+}$photosynthesis is accomplished on $\mathrm{BaO}_{\mathrm{NCs}}$-TNS $\left(89.79 \mathrm{mmol} \mathrm{g}_{\mathrm{cat}}-1 \mathrm{~h}^{-1}\right)$ with the reaction parameters of $100 \mathrm{mg} \mathrm{L}^{-1}$ of $\mathrm{NO}_{3}^{-}, 1.0 \mathrm{mg}$ of $\mathrm{BaO}_{\mathrm{NCs}^{-}}$-TNS catalyst, and UV light irradiation. It is worth mentioning that the introduction of UV light not only increases the energy density but also realizes the preactivation of $\mathrm{NO}_{3}^{-}$, which exceeds that of the full-spectrum $\left(15.80 \mathrm{mmol} \mathrm{g}_{\text {cat }}{ }^{-1} \mathrm{~h}^{-1}\right)$ and simulated solar light $\left(3.07 \mathrm{mmol} \mathrm{g}_{\text {cat }}{ }^{-1} \mathrm{~h}^{-1}\right)$. Then, as shown in the XRF results (Supplementary Fig. 10), 0.75 wt.\% of Ba element is detected in the $\mathrm{BaO}_{\mathrm{NCs}}$-TNS composite. Hence, the rate (per $\mathrm{Ba}$ metal) is 

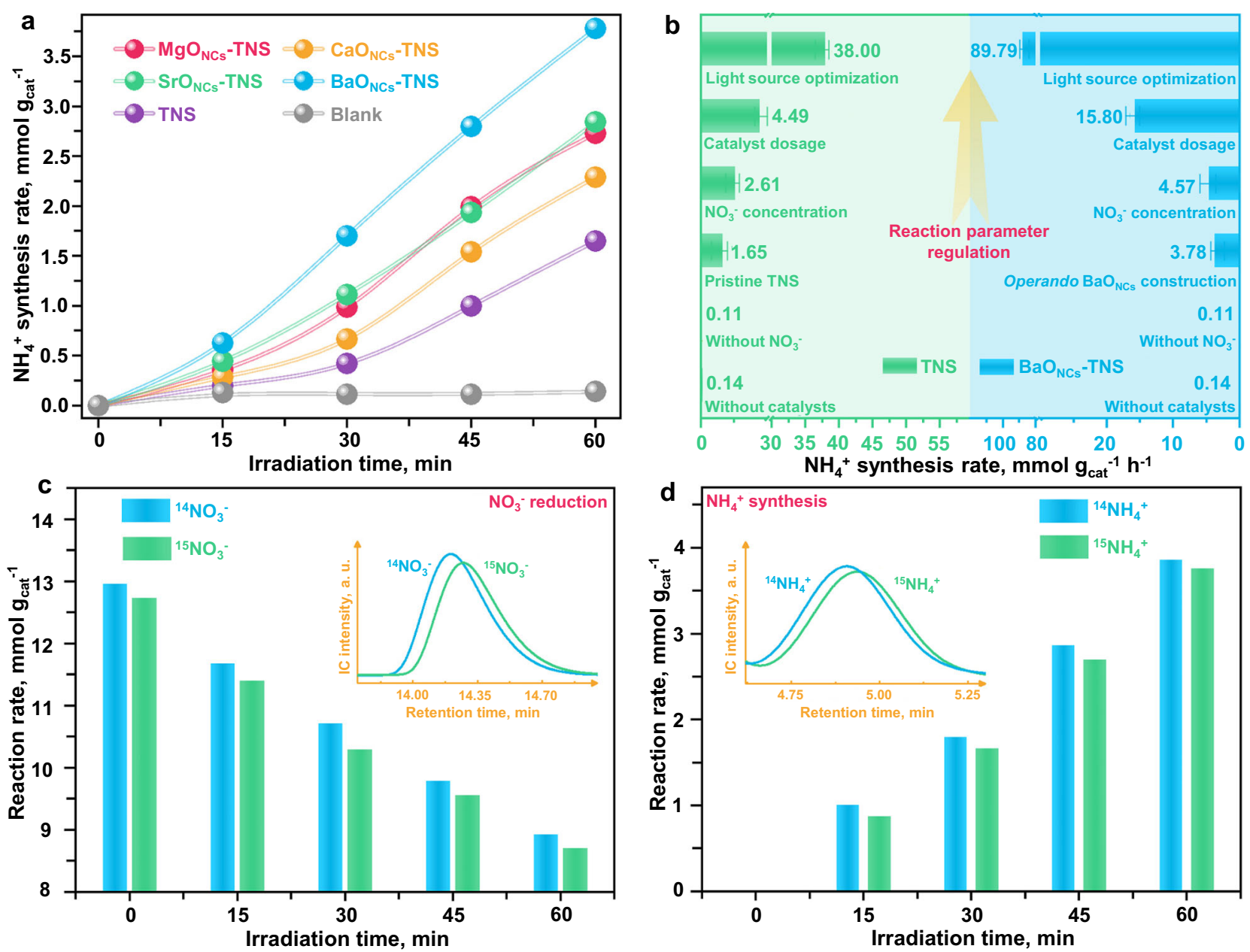

Fig. 3 Catalytic performance of $\mathbf{N H}_{\mathbf{3}}$ photosynthesis on alkaline-earth oxide clusters. a Catalytic efficiency tests showing the enhancement of operando construction of alkaline-earth oxide clusters on TNS surfaces. b Reaction parameter regulation for optimized $\mathrm{NH}_{4}{ }^{+}$photosynthesis rates on TNS and $\mathrm{BaO}_{\mathrm{NCs}^{-}}$-TNS respectively. c, $\mathbf{d}$ Quantitative isotope-labeled ${ }^{15} \mathrm{NO}_{3}{ }^{-}$study verifying the fed $\mathrm{NO}_{3}{ }^{-}$as the source for the prodcuced $\mathrm{NH}_{3}$. Inset: raw ion chromatography (IC) spectra for ${ }^{14} \mathrm{NO}_{3}-/ 15 \mathrm{NO}_{3}$ - reduction (c) and ${ }^{14} \mathrm{NH}_{4}{ }^{+} /{ }^{15} \mathrm{NH}_{4}{ }^{+}$generation (d) respectively. The $y$-axis of $\mathbf{c}$, $\mathbf{d}$ depict the reaction rates for $\mathrm{NO}_{3}{ }^{-}$reduction and $\mathrm{NH}_{4}{ }^{+}$production respectively. The inset images are the raw IC data for ${ }^{14} \mathrm{NO}_{3}{ }^{-} /{ }^{15} \mathrm{NO}_{3}-(\mathbf{c})$ and ${ }^{14} \mathrm{NH}_{4}{ }^{+} /{ }^{15} \mathrm{NH}_{4}{ }^{+}$ (d) respectively. The error bar was drawn based on the calculated standard error of two parallel tests.

calculated to be $11.97 \mathrm{~mol} \mathrm{~g}_{\mathrm{Ba}}{ }^{-1} \mathrm{~h}^{-1}$. The optimal rate catalyzed by $\mathrm{BaO}_{\mathrm{NCs}}-\mathrm{TNS}$ manifests advances in comparison with that of the other ammonia synthesis by using alkaline-earth-containing catalysts (Supplementary Table 1).

To exclude the potential contribution of contaminative $\mathrm{N}$-containing species, blank control experiments were subsequently performed (Supplementary Fig. 29) under the same testing procedure as that without catalysts and $\mathrm{NO}_{3}{ }^{-}$; these experiments confirm that almost no $\mathrm{NH}_{4}{ }^{+}$is produced. Most importantly, a quantitative isotope measurement was executed to test the $\mathrm{N}$ source for generating $\mathrm{NH}_{4}{ }^{+}$by combining IC and nuclear magnetic resonance (NMR) technologies (Fig. 3c, d and Supplementary Figs. 30-32). $\mathrm{K}^{14} \mathrm{NO}_{3}$ and $\mathrm{K}^{15} \mathrm{NO}_{3}$ solutions are used as $\mathrm{N}$ sources. Within $60 \mathrm{~min}$ of reaction, ${ }^{15} \mathrm{NH}_{4}{ }^{+}$is observably detected when ${ }^{15} \mathrm{NO}_{3}{ }^{-}$is employed. In addition, comparable rates for ${ }^{14} \mathrm{NO}_{3}{ }^{-} /{ }^{15} \mathrm{NO}_{3}{ }^{-}$reduction (Fig. 3c) and ${ }^{14} \mathrm{NH}_{4}{ }^{+} /{ }^{15} \mathrm{NH}_{4}{ }^{+}$production (Fig. 3d) are identified, confirming that the produced ammonia is directly derived from the nitrate feedstock, thus, the contribution of contaminative N-containing species to ammonia can be neglected.

We further investigated the selectivity of the $\mathrm{NO}_{3}{ }^{-} \mathrm{RR}$ for $\mathrm{NH}_{4}{ }^{+}$ photosynthesis on $\mathrm{BaO}_{\mathrm{NCs}}$ - TNS (Fig. 4a and Supplementary Figs. 33 and 34). After $3 \mathrm{~h}$ ' irradiation, $29.64 \mathrm{mmol} \mathrm{g}_{\mathrm{cat}}{ }^{-1} \mathrm{NO}_{3}{ }^{-}$is reduced to generate $29.26 \mathrm{mmolg}_{\mathrm{cat}}{ }^{-1} \mathrm{NH}_{4}{ }^{+}$. Besides, the amount of total N species remains stable in the reaction mixture throughout the entire reaction, which implies that the five-electron transfer for partial reduction of $\mathrm{NO}_{3}{ }^{-}$to $\mathrm{N}_{2}$ is effectively impeded.In addition, generated $\mathrm{H}_{2}$ is detected (Supplementary Fig. 35) since water splitting is the primary side reaction in our reaction system. Trace amounts $\left(2.79 \mathrm{mmol} \mathrm{g}_{\mathrm{cat}}{ }^{-1}\right.$ for $\left.3 \mathrm{~h}\right)$ of $\mathrm{H}_{2}$ are produced. By comparing the eight-electron $\mathrm{NO}_{3}{ }^{-} \mathrm{RR}$ and two-electron water splitting reaction, the selectivity for $\mathrm{NH}_{4}{ }^{+}$photosynthesis is determined to reach as high as $97.67 \%$. The $\mathrm{NH}_{4}{ }^{+}$synthesis rate and selectivity of the $\mathrm{NO}_{3}{ }^{-} \mathrm{RR}$ on $\mathrm{BaO}_{\mathrm{NCs}}$-TNS are superior among the routes under ambient conditions, exceeding that of the other photocatalytic $\mathrm{NO}_{3}-\mathrm{RR}$ works and even some leading electrocatalytic $\mathrm{NO}_{3}-\mathrm{RR}$ work (Fig. $4 \mathrm{~b}$ and Supplementary Table 2). Not surprisingly, the results of this work also exhibit advances in comparison with those of $\mathrm{N}_{2} \mathrm{RR}$ routes at ambient conditions, including electrocatalytic, photocatalytic, and photoelectrochemical methods. Subsequently, the reaction activation energy of $\mathrm{NO}_{3}{ }^{-}$ $\mathrm{NH}_{4}{ }^{+}$synthesis and water splitting for $\mathrm{H}_{2}$ production was calculated (Fig. 4c and Supplementary Fig. 36). A distinct activation energy decrease of $1.42 \mathrm{eV}$ is noted for the $\mathrm{NO}_{3}{ }^{-} \mathrm{RR}$ compared with that of the water splitting reaction, which can enable efficient inhibition of electron consumption for the side reaction. 

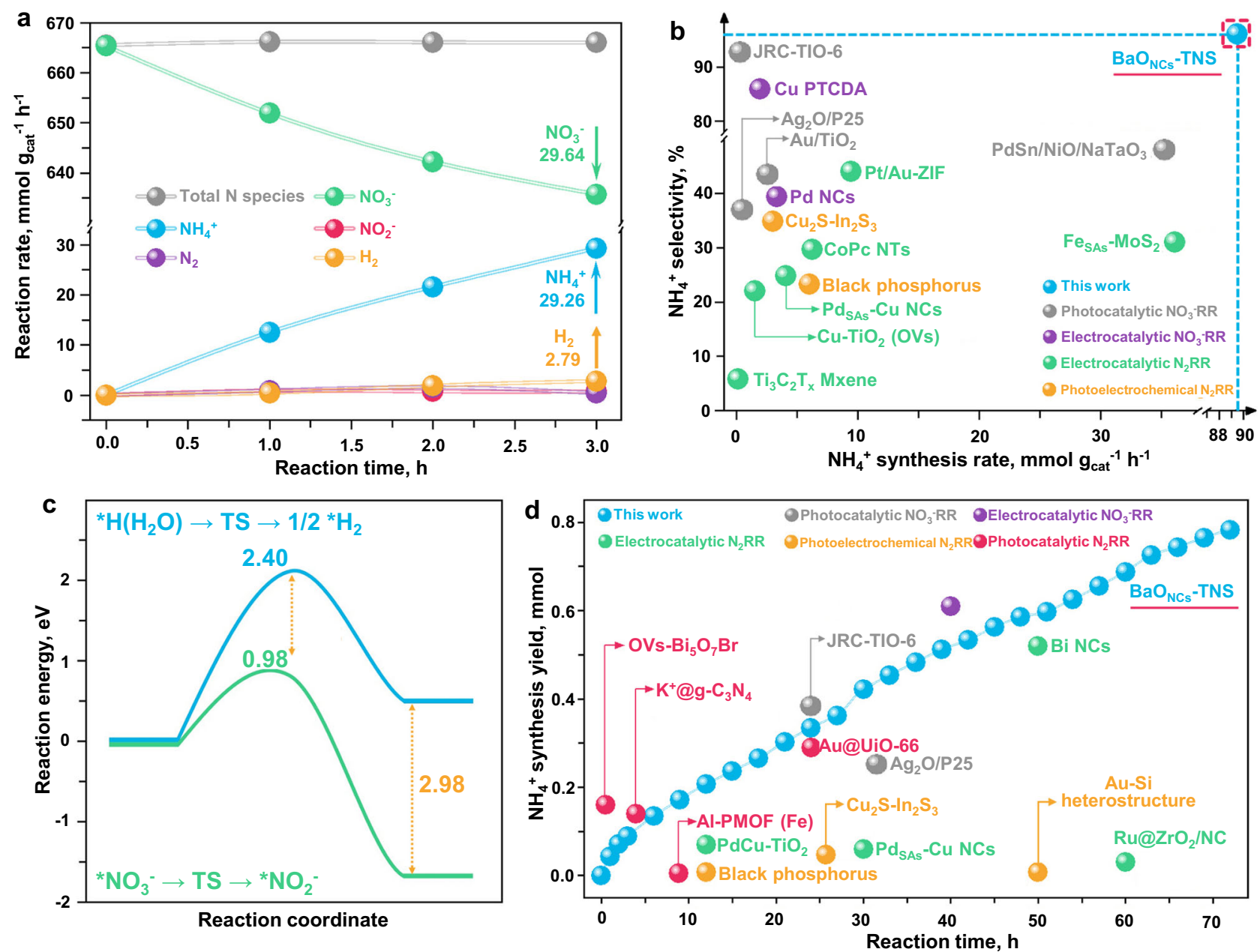

Fig. 4 Selectivity and long-term stability tests. a $\mathrm{NH}_{4}^{+}$selectivity test from $\mathrm{NO}_{3}-\mathrm{RR}$ versus the other potential products. The related stand curves were provided in Supplementary Figs. 37-39. b Comparison of $\mathrm{NH}_{4}{ }^{+}$production rate and selectivity with different ammonia synthesis routes under ambient conditions ${ }^{11,16,24,59-69}$. c Calculated activation energy for $\mathrm{NO}_{3}-\mathrm{RR}$ for $\mathrm{NH}_{4}+$ synthesis and water splitting for $\mathrm{H}_{2}$ generation. $\mathbf{d}$ Long-term stability of $\mathrm{BaO}_{\mathrm{NCs}^{-}}$-TNS and comparison of total $\mathrm{NH}_{4}{ }^{+}$yield with different $\mathrm{NH}_{4}{ }^{+}$synthesis routes $11,16,25,42,59,68-75$. The detailed comparison lists of $\mathbf{b}$ and $\mathbf{d}$ are provided in Supplementary Table 2.

Despite the ultra-high $\mathrm{NH}_{4}{ }^{+}$photosynthesis rate and selectivity, the total $\mathrm{NH}_{4}{ }^{+}$yield is a pivotal benchmark to evaluate the performance of ammonia synthesis catalysts and routes; notably, this benchmark is usually overlooked. Hence, long-term tests were performed to determine the accumulation of $\mathrm{NH}_{4}+$ (Fig. $4 \mathrm{~d}$ ). It is noted that a small amount of deactivation is observed in the first $3 \mathrm{~h}$, which may be caused by the competing reduction reaction of $\mathrm{Ba}^{2+}$ and $\mathrm{NO}_{3}{ }^{-}$. After the $\mathrm{BaO}_{\mathrm{NCs}}$ are stably formed on TNS, the significant stable production of $\mathrm{NH}_{4}{ }^{+}$on the $\mathrm{BaO}_{\mathrm{NCs}}$-TNS composite is realized. As a result, a total $\mathrm{NH}_{4}{ }^{+}$yield of $0.78 \mathrm{mmol}$ is reached within $72 \mathrm{~h}$. Moreover, the catalyst structure is well maintained after the long-term tests (Supplementary Figs. 40-43). By comparing the $\mathrm{NH}_{4}{ }^{+}$synthesis efficiency between the $\mathrm{NO}_{3}{ }^{-} \mathrm{RR}$ for $\mathrm{NH}_{4}{ }^{+}$photosynthesis and recently reported state-of-the-art routes (Supplementary Table 2), the $\mathrm{NH}_{4}{ }^{+}$synthesis rate, selectivity, long-term stability and total $\mathrm{NH}_{4}{ }^{+}$yield in this work all demonstrate advances in comparison with those of other ammonia synthesis routes under ambient conditions, including electrocatalytic, photocatalytic and photoelectrochemical methods. In addition, in the area of the $\mathrm{NO}_{3}-\mathrm{RR}$ for $\mathrm{NH}_{4}{ }^{+}$synthesis, the yield of photosynthesis in this work $(0.51 \mathrm{mmol}$ within $40 \mathrm{~h})$ is comparable to that of some leading work using electricity as the catalytic driving force $(0.61 \mathrm{mmol} \text { within } 40 \mathrm{~h})^{11}$. Since the density of energy input for photosynthesis is lower than that of electrocatalysis, the current photosynthesis performance of the $\mathrm{NO}_{3}{ }^{-} \mathrm{RR}$ for $\mathrm{NH}_{4}{ }^{+}$is very competitive.

Comprehensive understanding of the reaction mechanism. To further verify the active radicals responsible for the superior $\mathrm{NO}_{3}{ }^{-} \mathrm{RR}$ on the $\mathrm{BaO}_{\mathrm{NCs}}-\mathrm{TNS}$ composite, we applied the liquidstate EPR technology using 2,2,6,6-tetramethyl-1-piperidinyloxy (TEMPO) as the trapping reagent (Fig. 5a). The signals of TEMPO decrease rapidly on $\mathrm{BaO}_{\mathrm{NCs}}$-TNS compared with the TEMPO signals on pristine TNS under light irradiation; this result indicates that more photoexcited electrons are generated and consumed on $\mathrm{BaO}_{\mathrm{NCs}}$-TNS. The incorporation of $\mathrm{H}^{+}$and TEMPO- $\mathrm{e}^{-}$is significantly strengthened via the operando construction of subnanometric $\mathrm{BaO}_{\mathrm{NCs}}$, generating abundant active protons $\left(\mathrm{H}^{*}\right)$ to catalyze the $\mathrm{NO}_{3}{ }^{-} \mathrm{RR}$ for $\mathrm{NH}_{4}{ }^{+}$photosynthesis. In addition, enhanced ${ }^{\circ} \mathrm{OH},{ }^{\cdot} \mathrm{O}_{2}{ }^{-}$and ${ }^{1} \mathrm{O}_{2}$ production is also observed on $\mathrm{BaO}_{\mathrm{NCs}}$-TNS (Supplementary Fig. 44). These reactive oxygen species (ROS) are beneficial for the photocatalytic oxidation of EG, which facilitates hole consumption and charge separation.

Moreover, an in situ diffused reflectance infrared Fourier transform spectroscopy (DRIFTS) technique was introduced to dynamically detect the primary reaction process of the $\mathrm{NO}_{3}{ }^{-} \mathrm{RR}$. As 


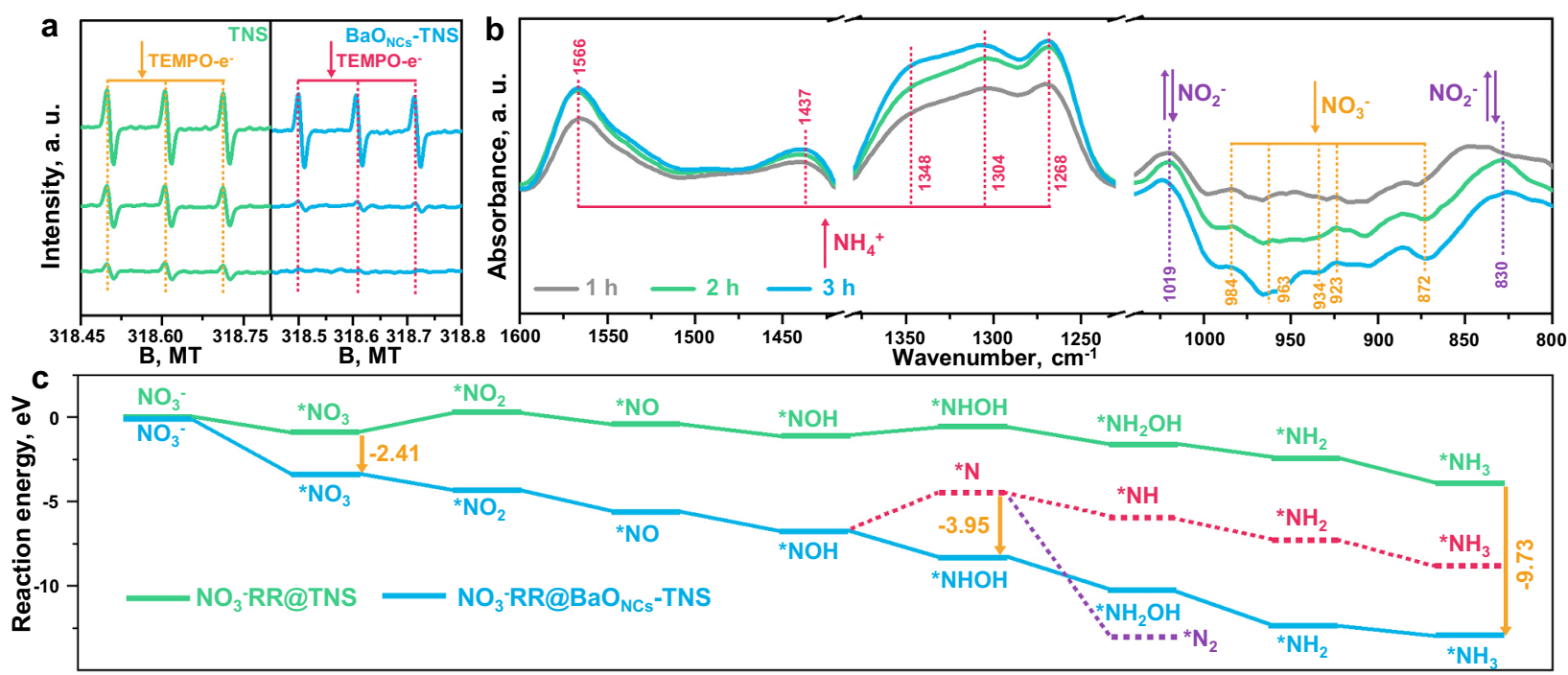

Reaction coordinate

Fig. 5 Molecular-level reaction mechanism of $\mathbf{N O}_{3}{ }^{-} \mathbf{R R}$ for $\mathbf{N H}_{3}$ photosynthesis. a EPR spectra for 2,2,6,6-tetramethyl-1-piperidinyloxy (TEMPO)-e ${ }^{-}$ showing the reactive species. $\mathbf{b}$ In situ diffused reflectance infrared Fourier transform spectroscopy (DRIFTS) revealing the principal reactants and products within the $\mathrm{NO}_{3}-\mathrm{RR}$ on $\mathrm{BaO}_{\mathrm{NCs}}$-TNS. c Gibbs free-energy diagram of the reaction coordinates. Steps marked red and purple are the potential side reactions of $\mathrm{NO}_{3}-\mathrm{RR}$ on $\mathrm{BaO}_{\mathrm{NCs}}-\mathrm{TNS}$.

shown in Fig. 4b, the characteristic peaks regarding adsorbed $\mathrm{NO}_{3}{ }^{-}$ are clearly identified at $872,923,934,969$, and $984 \mathrm{~cm}^{-1} 38,39$. It is noted that the intensity of $\mathrm{NO}_{3}{ }^{-}$gradually weakens with prolonged irradiation time, which confirms the consumption and reduction of $\mathrm{NO}_{3}{ }^{-}$. As the $\mathrm{NO}_{3}{ }^{-} \mathrm{RR}$ proceeds, the IR signals of the intermediate $\mathrm{NO}_{2}{ }^{-}$are observed at 830 and $1019 \mathrm{~cm}^{-1} 40,41$ and increase within the first two hours. After that, a decrease in the $\mathrm{NO}_{2}{ }^{-}$signals are noted (blue line in Fig. $4 \mathrm{~b}$ ), which illustrates that more $\mathrm{NO}_{2}{ }^{-}$has been consumed than generated. Most importantly, the continuous production of $\mathrm{NH}_{4}{ }^{+}$is verified $(1268,1304,1348,1437$, and $\left.1566 \mathrm{~cm}^{-1}\right)^{42-44}$. These results clarify that the $\mathrm{NO}_{3}{ }^{-} \mathrm{RR}$ route for $\mathrm{NH}_{4}{ }^{+}$photosynthesis is feasible, in which $\mathrm{NO}_{2}{ }^{-}$is identified as the principal intermediate product. Based on the in situ DRIFTS detection, the primary reaction pathways of the $\mathrm{NO}_{3}{ }^{-} \mathrm{RR}$ for $\mathrm{NH}_{4}{ }^{+}$ photosynthesis are summarized (Note 1).

Note 1 Primary reaction pathways of $\mathrm{NO}_{3}^{-}$reduction for $\mathrm{NH}_{4}{ }^{+}$photosynthesis

$$
\begin{gathered}
\mathrm{NO}_{3}^{-}+\mathrm{H}^{+} \rightarrow{ }^{*} \mathrm{NO}_{3}+{ }^{*} \mathrm{H} \\
{ }^{*} \mathrm{NO}_{3}+{ }^{\cdot} \mathrm{H} \rightarrow{ }^{*} \mathrm{NO}_{2}+{ }^{*} \mathrm{OH} \\
{ }^{*} \mathrm{NO}_{2}+\cdot{ }^{\bullet} \rightarrow{ }^{*} \mathrm{NO}+{ }^{*} \mathrm{OH} \\
{ }^{*} \mathrm{NO}+{ }^{\bullet} \mathrm{H} \rightarrow{ }^{*} \mathrm{NOH} \\
{ }^{*} \mathrm{NOH}+{ }^{\bullet} \mathrm{H} \rightarrow{ }^{*} \mathrm{NHOH} \\
{ }^{*} \mathrm{NHOH}+{ }^{\bullet} \mathrm{H} \rightarrow{ }^{*} \mathrm{NH}_{2} \mathrm{OH} \\
{ }^{*} \mathrm{NH}_{2} \mathrm{OH}+{ }^{\bullet} \mathrm{H} \rightarrow{ }^{*} \mathrm{NH}_{2}+\mathrm{H}_{2} \mathrm{O} \\
{ }^{*} \mathrm{NH}_{2}+{ }^{\bullet} \mathrm{H} \rightarrow{ }^{*} \mathrm{NH}_{3}
\end{gathered}
$$

The activation and reduction of $\mathrm{NO}_{3}{ }^{-}$on the catalyst surface were subsequently revealed by DFT calculations to support the experimental results. As depicted in Supplementary Fig. 45, the adsorption energy and received electrons of $\mathrm{NO}_{3}{ }^{-}$at the $\mathrm{BaO}_{\mathrm{NCs}} /$ TNS interface is observably elevated compared with that of pristine TNS, which could promote the $\mathrm{NO}_{3}{ }^{-}$reduction process.
Furthermore, the Gibbs free-energy diagrams $(\Delta G)$ were obtained to verify the effect of subnanometric $\mathrm{BaO}_{\mathrm{NCs}}$ construction on the reaction energy and pathways (Fig. 5c). Referring to the experimental results, we first compared the eight-electron transfer reaction for the synthesis of $\mathrm{NO}_{3}{ }^{-}-\mathrm{NH}_{3}$ on pristine TNS (green line in Fig. $5 \mathrm{c}$ and Supplementary Fig. 46) and $\mathrm{BaO}_{\mathrm{NCs}}$-TNS (blue line and Supplementary Fig. 47). It is clearly revealed that facile $\mathrm{NO}_{3}{ }^{-}$dissociation $\left({ }^{*} \mathrm{NO}_{3}{ }^{-}{ }^{*} \mathrm{NO}_{2}\right)$ can be accomplished on $\mathrm{BaO}_{\mathrm{NCs}}$-TNS with an observable decrease in energy compared to that of pristine TNS, which is the dominant reason for the elevated $\mathrm{NO}_{3}{ }^{-} \mathrm{RR}$ performance on $\mathrm{BaO}_{\mathrm{NCs}}-\mathrm{TNS}$. As the $\mathrm{NO}_{3}{ }^{-} \mathrm{RR}$ proceeds, a total energy decrease of $9.73 \mathrm{eV}$ is noted for efficient $\mathrm{NH}_{3}$ synthesis. Two primary competing reaction pathways regarding $\mathrm{N}_{2}$ and $\mathrm{NH}_{4}^{+}$production were compared (Supplementary Note 2 and 3). A lower $\Delta \mathrm{G}$ is required for ${ }^{*} \mathrm{NOH}-$ ${ }^{*} \mathrm{NHOH}(-1.63 \mathrm{eV})$ reduction than for ${ }^{*} \mathrm{NOH}-{ }^{*} \mathrm{~N}(+2.31 \mathrm{eV})$ reduction (red line in Fig. 5c and Supplementary Fig. 48). Since ${ }^{*} \mathrm{~N}$ generation is prevented, $\mathrm{N}_{2}$ production (purple line in Fig. $5 \mathrm{c}$ and Supplementary Fig. 49) is not an optional process on $\mathrm{BaO}_{\mathrm{NCs}}$-TNS. Besides, the lower activation energy for $\mathrm{NO}_{3}{ }^{-}$ dissociation $(0.98 \mathrm{eV}$, Fig. $4 \mathrm{c})$ is identified in comparison with that of the water splitting reaction $(2.40 \mathrm{eV})$. Hence, among the three potential products in these reaction pathways $\left(\mathrm{NH}_{4}{ }^{+}, \mathrm{N}_{2}\right.$ and $\mathrm{H}_{2}$ ), the highly selective eight-electron reduction of $\mathrm{NO}_{3}{ }^{-}$for $\mathrm{NH}_{4}{ }^{+}$photosynthesis is achieved via the assistance of $\mathrm{MO}_{\mathrm{NCs}}$.

Practical applications of $\mathrm{NO}_{3}{ }^{-} \mathrm{RR}$ in simulated wastewater. The practical application of the as-proposed $\mathrm{NO}_{3}{ }^{-} \mathrm{RR}$ for ammonia photosynthesis route was developed. Since the organic matter of EG is applied in the catalysis system (Catal. Sys.) as the hole sacrificial agent, the conversion pathways of EG are investigated via the in situ DRIFTS technology (Fig. 6a). It is observed that the dynamic adsorption equilibrium (Ads. Equil.) of EG is gradually formed based on the detection of methane $\left(2940,2880,1437 \text {, and } 1364 \mathrm{~cm}^{-1}\right)^{45,46}$ and alcohol $\left(1123,1080 \text {, and } 1040 \mathrm{~cm}^{-1}\right)^{45,47}$ species. Then the generation and accumulation of formate $\left(1153 \mathrm{~cm}^{-1}\right)^{48}$ and carbonate $\left(1285 \mathrm{~cm}^{-1}\right)^{46,47}$ are observed, which can be attributed to the primary products for EG oxidation. Hence, it is concluded that the reactions of EG oxidation and $\mathrm{NO}_{3}{ }^{-}$reduction proceed 

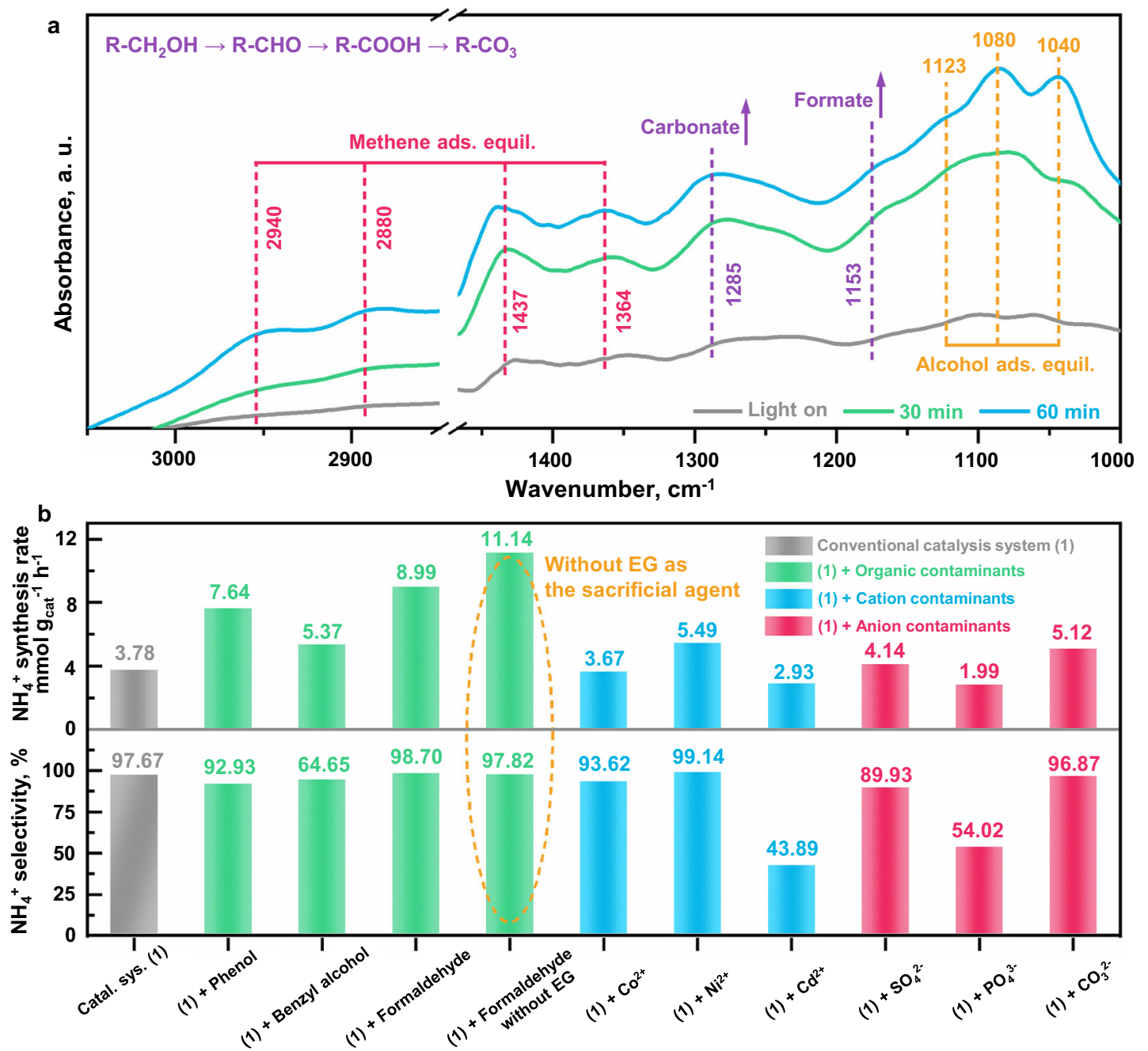

Fig. 6 Practical application of $\mathbf{N O}_{3}{ }^{-} \mathbf{R R}$ to $\mathbf{N H}_{4}{ }^{+}$route in simulated wastewater. a In situ DRIFTS for ethylene glycol (EG, hole sacrificial agent) oxidation during the $\mathrm{NO}_{3}-\mathrm{RR}$. $\mathbf{b}$ Ammonia synthesis rates and selectivity evaluation by adding different types of simulated wastewater into the catalysis system (Catal. Sys.), including the organic matter (phenol, benzyl alcohol and formaldehyde), cation $\left(\mathrm{Co}^{2+}, \mathrm{Ni}^{2+}\right.$ and $\mathrm{Cd}^{2+}$ ) and anion $\left(\mathrm{SO}_{4}{ }^{2-}, \mathrm{PO}_{4}{ }^{3-}\right.$ and $\mathrm{CO}_{3}{ }^{2-}$ ) contaminants correspondingly. As for the condition of formaldehyde, the catalytic tests were conducted with and without EG respectively.

simultaneously, in which the hole consumption by EG oxidation could in turn accelerate the $\mathrm{NO}_{3}{ }^{-} \mathrm{RR}$ to promote ammonia synthesis.

Most importantly, it should be noted that abundant organic contaminants are distributed in many $\mathrm{NO}_{3}{ }^{-}$-containing emission conditions such as agricultural and chemical wastewater degradation and drinking water purification, in which the organic contaminants can be utilized as what is called the hole sacrificial agent. Based on this consideration, phenol, benzyl alcohol and formaldehyde were added into the catal. sys. as potential contaminants respectively (Fig. $6 \mathrm{~b}$ and Supplementary Fig. 50a-f). It is found that the ammonia synthesis rates and selectivity are all retained, which indicates that the $\mathrm{NO}_{3}{ }^{-} \mathrm{RR}$ route is established in the simulated organic wastewater. Interestingly, the ammonia synthesis rates are increased in the order of conventional catal. sys. $\left(3.78 \mathrm{mmol} \mathrm{g}^{-1} \mathrm{~h}^{-1}\right)<$ benzyl alcohol $\left(5.37 \mathrm{mmol} \mathrm{g}^{-1} \mathrm{~h}^{-1}\right)<$ phenol $\left(7.64 \mathrm{mmol} \mathrm{g}^{-1} \mathrm{~h}^{-1}\right)<$ formaldehyde $\left(8.99 \mathrm{mmol} \mathrm{g}^{-1} \mathrm{~h}^{-1}\right)$. It is deduced that the hole consumption capacity of these organic contaminants is higher than that of EG, which leaves more electrons to catalyze the $\mathrm{NO}_{3}-\mathrm{RR}$. Then, the corresponding test of formaldehyde was conducted without EG as the hole sacrificial agent (Fig. $6 \mathrm{~b}$ and Supplementary Fig. 50g-h). It is observed that the ammonia synthesis rate is further elevated to $11.14 \mathrm{mmol} \mathrm{g}^{-1} \mathrm{~h}^{-1}$ with $97.82 \%$ of selectivity noted, which reveals that the formaldehyde can act as the "hole sacrificial agent" more efficiently than that of EG. Based on the organic contaminant investigation in the simulated wastewater, it is clarified that the $\mathrm{NO}_{3}{ }^{-} \mathrm{RR}$ route can be developed as a "sacrificial-agent-free" technology for the application of ammonia synthesis in wastewater coupled with the organic pollutants' oxidation, which demonstrates scientific significance in both areas of environmental remediation and energy conversion. Besides, the addition of cation contaminants $\left(\mathrm{Co}^{2+}, \mathrm{Ni}^{2+}\right.$, and $\mathrm{Cd}^{2+}$, Supplementary Fig. 51) and anion contaminants $\left(\mathrm{SO}_{4}{ }^{2+}, \mathrm{PO}_{4}{ }^{3-}\right.$ and $\mathrm{CO}_{3}{ }^{2-}$, Supplementary Fig. 52) have also been considered, in which the catalytic efficiency is accomplished in general. Some discrepancy in the performance is noted among these ions, which could be raised by the complicated impact of added ions on the catal. sys. and requires further investigation in the future.

\section{Discussion}

In summary, a highly active and selective $\mathrm{NO}_{3}{ }^{-} \mathrm{RR}$ for $\mathrm{NH}_{4}{ }^{+}$ photosynthesis was achieved by operando construction of subnanometric $\mathrm{MO}_{\mathrm{NCs}}$ on TNS. The dynamic evolution pattern, growth mechanism, and interfacial structure of $\mathrm{MO}_{\mathrm{NCs}}$ were characterized and well-defined. A superior $\mathrm{NH}_{4}{ }^{+}$photosynthesis rate, selectivity, long-term stability and total yield were achieved among the various $\mathrm{NH}_{4}{ }^{+}$synthesis routes under ambient 
conditions. Then it was proposed that the unique electronic structure at the $\mathrm{MO}_{\mathrm{NCS}} / \mathrm{TNS}$ interface was mainly responsible for the enhanced $\mathrm{NO}_{3}{ }^{-}$dissociation and eight-electron reduction reaction. The practical application of $\mathrm{NO}_{3}{ }^{-} \mathrm{RR}$ route in simulated wastewater was developed, which demonstrated scientific significance in both areas of environmental remediation and energy conversion. The discovery of subnanometric $\mathrm{MO}_{\mathrm{NCs}}$ for sustainable $\mathrm{NO}_{3}{ }^{-}-\mathrm{NH}_{4}{ }^{+}$photosynthesis is inspiring and is of general knowledge, thereby providing numerous opportunities for research into cluster chemistry and artificial photosynthesis.

\section{Methods}

Chemicals. All chemicals were purchased without further treatment. The respective source and purity were listed in Supplementary Table 3.

Synthesis of TNS. The synthesis of $\mathrm{TiO}_{2}$ nanosheets (TNS) was conducted via slight modification of the reported work ${ }^{49,50}$. In a typical preparation procedure, $3 \mathrm{~mL}$ of $\mathrm{HF}$ solution was dropped slowly into $25 \mathrm{~mL}$ of Ti $(\mathrm{OBu})_{4} \cdot(\mathrm{TBOT})$ under continuous magnetic stirring for $2 \mathrm{~h}$ until the solution formed into a gel-like solution. Then the mixture was transferred into a Teflon autoclave with a volume of $50 \mathrm{~mL}$ and then heated at $180^{\circ} \mathrm{C}$ for $24 \mathrm{~h}$. After naturally cooling down to room temperature, the powder was separated and collected by high-speed centrifugation at $10,000 \mathrm{rpm}$ for $5 \mathrm{~min}$ with distilled water (DI) and ethanol washing for at least 10 times respectively, which removes the residual organic matter and $\mathrm{F}^{-}$. At last, the obtained sample was dried at $80^{\circ} \mathrm{C}$ overnight in the vacuum drying oven.

Construction of $\mathbf{M O}_{\mathbf{N C s}}$ on TNS. Five milligrams of TNS powder was dispersed in $100 \mathrm{~mL}$ of reaction solution containing $10 \mathrm{mg} / \mathrm{L}$ of $\mathrm{NO}_{3}{ }^{-}-\mathrm{N}, 50 \mathrm{mg} / \mathrm{L}$ of alkaline earth chlorides $\left(\mathrm{MgCl}_{2}, \mathrm{CaCl}_{2}, \mathrm{SrCl}_{2}\right.$, and $\mathrm{BaCl}_{2}$ respectively) and $10 \mathrm{~mL}$ EG. Then the mixture was transferred into a photocatalytic reactor (MC-GF250, Merry Change, China) and degassed for soluble air with high-purity $\operatorname{Ar}(99.999 \%)$ at $50 \mathrm{~mL} / \mathrm{min}$ for $30 \mathrm{~min}$ under stirring. A $300 \mathrm{~W}$ Xe lamp (MC-X301B, Merry Change, China) was used at the light source. After 1 h's irradiation with continuous Ar pumping and stirring, the obtained powder was collected by washing with ethanol and DI for three times respectively. With the irradiation on stream, the reaction mixture was extracted several times for the tests of $\mathrm{M}^{\mathrm{X}+}$ concentration and operando evolution of $\mathrm{MO}_{\mathrm{NCs}}$ on the substrate surface.

Catalyst characterization. The crystal information was examined by the X-ray diffraction (XRD, model D/max RA, Rigaku Co.) technology. The morphology was surveyed by scanning electron microscopy (SEM, XL30 ESEM FEG), transmission electron microscopy (TEM, FEI Talos F200S). The operando evolution of $\mathrm{MO}_{\mathrm{NCs}}$ was verified by quasi in situ high-angle annular dark-field scanning transmission electron microscopy (HAADF-STEM, JEOL JEM-ARM200F) with spherical aberration correction to investigate the morphology at the atomic scale. The chemical composition was tested via the X-ray photoelectron spectroscopy (XPS, Thermo Scientific K-Alpha plus) with an $\mathrm{Al} \mathrm{Ka} \mathrm{X-ray} \mathrm{light} \mathrm{source.} \mathrm{The} \mathrm{elemental} \mathrm{com-}$ ponent analysis was conducted by X-ray fluorescence (XRF, BRUKER, M4 TORNADO). The solid-state EPR (JES FA200) spectra were performed to identify the vacancy signals.

Optical and electronic property identification. The light absorption capacity was performed by a scanning UV-vis spectrophotometer (Shimadzu UV-2450) outfitted with an integrating sphere, using barium sulfate as the comparison sample. The Mott-Schottky spectra were conducted using catalysts/C, $\mathrm{Ag} / \mathrm{AgCl}$ and $\mathrm{Pt}$ as working, reference and counter electrodes respectively on an electrochemical workstation (CHI-660E), and the results were recorded from -1.0 to $1.5 \mathrm{~V}$ at $1000 \mathrm{~Hz}$ without light irradiation. The steady photoluminescence (PL) spectra were investigated using a fluorescence spectrophotometer (Edinburgh Instruments FLSP-920). Time-resolved fluorescence emission decay spectra (PicoQuant Fluotime 300) were carried out to verify the carrier's life time under light irradiation. The liquid-state EPR spectra of active radicals were obtained on a JES FA200 spectrometer to investigate the production of the ROS under light illumination. The 5, 5-Dimethyl-1-Pyrroline-N-Oxide (DMPO) was used as the trapping agent to confirm the involvement of DMPO- ${ }^{\circ} \mathrm{OH}$ and DMPO- ${ }^{-} \mathrm{O}_{2}{ }^{-}$respectively in aqueous methanol dispersion. 4-oxo-2, 2, 6, 6-Tetramethyl-1-Piperidinyloxy (TEMP) was applied to survey the TEMP- ${ }^{1} \mathrm{O}_{2}$ and TEMP-1-oxyl (TEMPO) was used to characterize the photo-induced electrons $\left(\right.$ TEMPO- $\mathrm{e}^{-}$).

DFT calculation. The spin-polarized DFT calculations were operated with the "Vienna ab initio simulation package" (VASP 5.4), in which the PBE exchangecorrelation functional was included ${ }^{51-53}$. The PBE $+U$ correction $(U=4.0 \mathrm{eV})$ was implemented to account for the on-site charge interaction of the delectrons in $\mathrm{Ti}$ elements ${ }^{54}$, which improved the accuracy for the calculations of electron migration at the $\mathrm{MO}_{\mathrm{NCs}}-\mathrm{TNS}$ interfaces. The cut-off energy was set to $400 \mathrm{eV}$. K points in the Brillouin zone were set to $5 \times 5 \times 1$ for both structural and electronic optimization.
Geometry relaxation was achieved after the residual forces were smaller than $0.01 \mathrm{eV} \AA^{-1}$. The Gaussian smearing width was set to $0.2 \mathrm{eV}$. The initial calculation model of TNS contains $60 \mathrm{Ti}$ atoms and $120 \mathrm{O}$ atoms respectively (Supplementary Fig. 12a). The typical [001] facet is exposed for further calculations. The lattice parameters were set to $11 \times 15 \times 25 \AA^{3}$, which contains a vacuum slab of $15 \AA$ to impede the potential interaction between neighboring lattices. The initial calculation models of $\mathrm{MgO}_{\mathrm{NCs}}, \mathrm{CaO}_{\mathrm{NC}}, \mathrm{SrO}_{\mathrm{NCs}}$ and $\mathrm{BaO}_{\mathrm{NCs}}$ were constructed with the cluster size of $0.73,0.83,0.89$, and $0.96 \mathrm{~nm}$ respectively (Supplementary Fig. 12b-e)

The adsorption energy $\left(E_{\text {ads }}\right)$ for molecules was calculated as follows:

$$
E_{\text {ads }}=E_{\text {tot }}-E_{\text {cat. }}-E_{\text {mol }}
$$

where $E_{\mathrm{to}}, E_{\mathrm{cat}}$, and $E_{\mathrm{mol}}$ depicted the total energy of adsorption structure, catalyst support, and isolated molecule respectively.

The Gibbs free energy variation $(\Delta G)^{55,56}$ between the initial state (IS) and final state (FS) was determined with the following equation

$$
\Delta G=E_{\mathrm{FS}}-E_{\mathrm{IS}}+\Delta E_{\mathrm{ZPE}}-T \Delta S
$$

where $E_{\mathrm{FS}}$ and $E_{\mathrm{IS}}$ referred to the DFT total energy for FS and IS correspondingly. $\Delta E_{\mathrm{ZPE}}$ and $\Delta S$ denoted the variation of zero-point energy and entropy. The room temperature $(T, 298.15 \mathrm{~K})$ was applied.

The climbing image-nudged elastic band (CI-NEB) $)^{57,58}$ code was conducted to identify the reaction coordinates from IS to FS, which located the transition state (TS) with single imaginary frequency verification. The activation energy $\left(E_{\mathrm{a}}\right)$ and reaction energy $\left(E_{\mathrm{r}}\right)$ were defined as follows

$$
\begin{aligned}
& E_{\mathrm{a}}=E_{\mathrm{TS}}-E_{\mathrm{IS}} \\
& E_{\mathrm{r}}=E_{\mathrm{FS}}-E_{\mathrm{IS}}
\end{aligned}
$$

where $E_{\mathrm{IS}}, E_{\mathrm{TS}}$, and $E_{\mathrm{FS}}$ were DFT calculated total energy of IS, TS, and FS respectively.

$\mathrm{NO}_{3}{ }^{-}-\mathrm{NH}_{\mathbf{4}}{ }^{+}$photosynthesis efficiency test. Photosynthesis tests were first conducted to determine the activity enhancement by operando $\mathrm{MO}_{\mathrm{NCs}}$ construction. In a typical experimental procedure, $5 \mathrm{mg}$ of TNS powder was dispersed in $100 \mathrm{~mL}$ of reaction solution containing $10 \mathrm{mg} / \mathrm{L}$ of $\mathrm{NO}_{3}{ }^{-}-\mathrm{N}, 50 \mathrm{mg} / \mathrm{L}$ of alkaline earth chlorides $\left(\mathrm{MgCl}_{2}, \mathrm{CaCl}_{2}, \mathrm{SrCl}_{2}\right.$, and $\mathrm{BaCl}_{2}$ respectively) and $10 \mathrm{~mL}$ EG. Then the mixture was transferred into a photocatalytic reactor (MC-GF250, Merry Change, China) and degassed for soluble air with $\mathrm{Ar}$ at $50 \mathrm{~mL} / \mathrm{min}$ for $30 \mathrm{~min}$ under stirring. A $300 \mathrm{~W}$ Xe lamp (MC-X301B, Merry Change, China) was used at the light source. After the photocatalysis reaction, the operando construction of $\mathrm{MO}_{\mathrm{NCs}}$ on TNS is accomplished. The photocatalysts were collected and washed for further characterization. The blank control experiment was also performed, which excluded the catalysts and $\mathrm{NO}_{3}{ }^{-}-\mathrm{N}$ respectively. The consumed $\mathrm{NO}_{3}{ }^{-}$and produced $\mathrm{NH}_{4}{ }^{+}$were both detected by ion chromatography (IC, Shimadzu IC-16 for $\mathrm{NH}_{4}{ }^{+}$and Analysis Lab CS2000 for $\mathrm{NO}_{3}{ }^{-}$respectively). After that, the reaction parameter was comprehensively optimized to obtain the optimal $\mathrm{NH}_{4}{ }^{+}$photosynthesis efficiency, which included $\mathrm{NO}_{3}{ }^{-}-\mathrm{N}$ concentration (from 10 to $500 \mathrm{mg} / \mathrm{L}$ ), catalyst dosage (from 0.5 to $5 \mathrm{mg}$ ) and the irradiation source (UV, full spectrum and simulated solar light). The $\mathrm{pH}$ of this catalytic system remains at ca. 7.0 during the test since the $\mathrm{KNO}_{3}$ and EG consist of neutral solutions (Supplementary Fig. 53). The temperature is controlled at $25^{\circ} \mathrm{C}$ by using the circulating chiller (Supplementary Fig. 54).

The quantitative ${ }^{15} \mathrm{~N}$ isotope tracing measurement was conducted, using $10 \mathrm{mg} / \mathrm{L}$ of $\mathrm{K}^{14} \mathrm{NO}_{3}$ and $\mathrm{K}^{15} \mathrm{NO}_{3}$ as the feedstock respectively, the produced ${ }^{14} \mathrm{NH}_{4}{ }^{+}$and ${ }^{15} \mathrm{NH}_{4}{ }^{+}$ were quantified by IC. Then the ${ }^{1} \mathrm{H}$ NMR (Bruker $400 \mathrm{M}$ ) was used to complement the IC results. As for the long-term stability test, the $\mathrm{NO}_{3}{ }^{-}-\mathrm{N}$ concentration was increased to $500 \mathrm{mg} / \mathrm{L}$ to guarantee sufficient feedstock. Meanwhile, the catalyst dosage was increased to $50 \mathrm{mg}$ to elevate the total yield of $\mathrm{NH}_{4}{ }^{+}$. In order to investigate the $\mathrm{NH}_{4}{ }^{+}$ selectivity, the $\mathrm{H}_{2}$ was also detected during the $\mathrm{NO}_{3}{ }^{-} \mathrm{RR}$, using gas chromatography (Kechuang GC 2002) with the thermal conductivity detector (TCD). The selectivity was calculated as follows

$\mathrm{NH}_{4}^{+}$Selectivity $=\left[8\right.$ Yield $\left.\left(\mathrm{NH}_{4}^{+}\right)\right] /\left[2\right.$ Yield $\left(\mathrm{H}_{2}\right)+5$ Yield $\left(1 / 2 \mathrm{~N}_{2}\right)+8$ Yield $\left.\left(\mathrm{NH}_{4}^{+}\right)\right] \times 100 \%$

In situ DRIFTS investigation. In situ diffuse reflectance infrared Fourier transform spectroscopy (DRIFTS, Bruker INVENIO R) was utilized to monitor the adsorbed species on the $\mathrm{BaO}_{\mathrm{NC}}$ - TNS surface within the reaction process, in which an in situ diffuse-reflectance cell (Harrick) and a reaction chamber (HVC) were equipped. Before measurement, the catalyst was mixed into $100 \mathrm{mg} / \mathrm{L}$ of $\mathrm{NO}_{3}{ }^{-}-\mathrm{N}$ solution by continuous stirring and then dried at $110^{\circ} \mathrm{C}$ in a vacuum drying oven. The as-prepared sample was transferred in the reaction chamber and heated for $30 \mathrm{~min}$ at $110^{\circ} \mathrm{C}$ to completely remove the adsorbed species on the surface. Highpurity $\mathrm{He}(99.999 \%)$ was continuously pumped into the reaction system to maintain the inert atmosphere. A Xe lamp was used as the light source. The IR detection was conducted during the light irradiation.

Practical applications in simulated wastewater. Some potential contaminants were added into the catalysis system of $\mathrm{BaO}_{\mathrm{NCs}}$-TNS to evaluate the $\mathrm{NO}_{3}{ }^{-} \mathrm{RR}$ 
performance in simulated wastewater, including phenol, benzyl alcohol, and formaldehyde as organic matters, $\mathrm{Co}^{2+}, \mathrm{Ni}^{2+}$, and $\mathrm{Cd}^{2+}$ as cations, $\mathrm{SO}_{4}{ }^{2-}, \mathrm{PO}_{4}{ }^{3-}$ and $\mathrm{CO}_{3}{ }^{2-}$ as anions respectively. $\mathrm{CoCl}_{2}, \mathrm{NiCl}_{2}$, and $\mathrm{CdCl}_{2}$ were used as the source of cations. $\mathrm{K}_{2} \mathrm{SO}_{4}, \mathrm{~K}_{3} \mathrm{PO}_{4}$, and $\mathrm{K}_{2} \mathrm{CO}_{3}$ were used as the source of anions respectively. Based on the formaldehyde test, the $\mathrm{EG}$ is excluded from the reaction mixture for comparison. The concentration variation of $\mathrm{SO}_{4}{ }^{2-}, \mathrm{PO}_{4}{ }^{3-}$, and $\mathrm{CO}_{3}{ }^{2-}$ is determined by ion chromatograph (Shimadzu IC-16). An inductive coupled plasma emission spectrometer (Agilent ICPOES730) is applied to reveal the concentration of $\mathrm{Co}^{2+}, \mathrm{Ni}^{2+}$, and $\mathrm{Cd}^{2+}$. Phenol and benzyl alcohol were tested on the liquid chromatography (Shimadzu LC-20AT). In addition, we measured the concentration of formic acid as the oxidative product of formaldehyde by IC (Shimadzu IC-16)

\section{Data availability}

All data generated in this study are provided in the Source Data files, in which the data presented in Figures from the Maintext and Supplementary Information are listed in the Excel files of Source Data 1 and Source Data 2 respectively.

\section{Code availability}

Only the commercial codes were used in this work (See references).

Received: 14 September 2021; Accepted: 8 February 2022;

Published online: 01 March 2022

\section{References}

1. Rod, T. H., Logadottir, A. \& Norskov, J. K. Ammonia synthesis at low temperatures. J. Chem. Phys. 112, 5343-5347 (2000).

2. Chen, J. G. et al. Beyond fossil fuel-driven nitrogen transformations. Science 360, eaar6611 (2018).

3. Ye, T. N. et al. Vacancy-enabled $\mathrm{N}_{2}$ activation for ammonia synthesis on an Ni-loaded catalyst. Nature 583, 391-395 (2020).

4. Comer, B. M. et al. Prospects and challenges for solar fertilizers. Joule 3, 1578-1605 (2019).

5. Qing, G. et al. Recent advances and challenges of electrocatalytic $\mathrm{N}_{2}$ reduction to ammonia. Chem. Rev. 120, 5437-5516 (2020).

6. Guo, J. \& Chen, P. Interplay of alkali, transition metals, nitrogen, and hydrogen in ammonia synthesis and decomposition reactions. Acc. Chem. Res. 54, 2434-2444 (2021).

7. Lehnert, N., Dong, H. T., Harland, J. B., Hunt, A. P. \& White, C. J. Reversing nitrogen fixation. Nat. Rev. Chem. 2, 278-289 (2018)

8. Minteer, S. D., Christopher, P. \& Linic, S. Recent developments in nitrogen reduction catalysts: a virtual issue. ACS Energy Lett. 4, 163-166 (2019).

9. Wang, Y., Wang, C., Li, M., Yu, Y. \& Zhang, B. Nitrate electroreduction: mechanism insight, in situ characterization, performance evaluation, and challenges. Chem. Soc. Rev. 50, 6720-6733 (2021).

10. Li, J. et al. Efficient ammonia electrosynthesis from nitrate on strained ruthenium nanoclusters. J. Am. Chem. Soc. 142, 7036-7046 (2020).

11. Chen, G. F. et al. Electrochemical reduction of nitrate to ammonia via direct eight-electron transfer using a copper-molecular solid catalyst. Nat. Energy 5 , 605-613 (2020).

12. van Langevelde, P. H., Katsounaros, I. \& Koper, M. T. M. Electrocatalytic nitrate reduction for sustainable ammonia production. Joule 5, 1-5 (2021).

13. $\mathrm{Wu}, \mathrm{Z}$. Y. et al. Electrochemical ammonia synthesis via nitrate reduction on $\mathrm{Fe}$ single atom catalyst. Nat. Commun. 12, 2870 (2021).

14. Li, L. et al. Efficient nitrogen fixation to ammonia through integration of plasma oxidation with electrocatalytic reduction. Angew. Chem. Int. Ed. 60, 14131-14137 (2021).

15. Liu, Y. et al. Pothole-rich ultrathin $\mathrm{WO}_{3}$ nanosheets that trigger $\mathrm{N}$ identical with $\mathrm{N}$ bond activation of nitrogen for direct nitrate photosynthesis. Angew. Chem. Int. Ed. 58, 731-735 (2019).

16. Hirakawa, H., Hashimoto, M., Shiraishi, Y. \& Hirai, T. Selective nitrate-toammonia transformation on surface defects of titanium dioxide photocatalysts. ACS Catal. 7, 3713-3720 (2017).

17. Zhang, X. et al. Recent advances in non-noble metal electrocatalysts for nitrate reduction. Chem. Eng. J. 403, 126269 (2021).

18. Zhou, L. et al. Electron flow shifts from anode-respiration to nitrate reduction during electroactive biofilm thickening. Environ. Sci. Technol. 54, 9593-9600 (2020).

19. Kani, N. C. et al. Solar-driven electrochemical synthesis of ammonia using nitrate with $11 \%$ solar-to-fuel efficiency at ambient conditions. Energy Environ. Sci. 14, 6349-6359 (2021)

20. Gao, Z. et al. Constructing well-defined and robust Th-MOF-supported single-site copper for production and storage of ammonia from electroreduction of nitrate. ACS Cent. Sci. 7, 1066-1072 (2021).
21. Smith, K. E. C. \& Jeong, Y. Passive sampling and dosing of aquatic organic contaminant mixtures for ecotoxicological analyses. Environ. Sci. Technol. 55, 9538-9547 (2021)

22. Wang, Y., Zhou, W., Jia, R., Yu, Y. \& Zhang, B. Unveiling the activity origin of a copper-based electrocatalyst for selective nitrate reduction to ammonia. Angew. Chem. Int. Ed. 59, 5350-5354 (2020).

23. Li, P., Jin, Z., Fang, Z. \& Yu, G. A single-site iron catalyst with preoccupied active centers that achieves selective ammonia electrosynthesis from nitrate. Energy Environ. Sci. 14, 3522-3531 (2021).

24. Lim, J. et al. Structure sensitivity of Pd facets for enhanced electrochemical nitrate reduction to ammonia. ACS Catal. 11, 7568-7577 (2021).

25. Hao, Y.-C. et al. Promoting nitrogen electroreduction to ammonia with bismuth nanocrystals and potassium cations in water. Nat. Catal. 2, 448-456 (2019).

26. Xue, X. et al. Review on photocatalytic and electrocatalytic artificial nitrogen fixation for ammonia synthesis at mild conditions: advances, challenges and perspectives. Nano Res. 12, 1229-1249 (2019).

27. Jiang, $\mathrm{K}$. et al. Metal ion cycling of $\mathrm{Cu}$ foil for selective $\mathrm{C}-\mathrm{C}$ coupling in electrochemical $\mathrm{CO}_{2}$ reduction. Nat. Catal. 1, 111-119 (2018).

28. Liu, L. \& Corma, A. Confining isolated atoms and clusters in crystalline porous materials for catalysis. Nat. Rev. Mater. 6, 244-263 (2021).

29. Babucci, M., Guntida, A. \& Gates, B. C. Atomically dispersed metals on welldefined supports including zeolites and metal-organic frameworks: structure, bonding, reactivity, and catalysis. Chem. Rev. 120, 11956-11985 (2020).

30. Corma, A. et al. Exceptional oxidation activity with size-controlled supported gold clusters of low atomicity. Nat. Chem. 5, 775-781 (2013).

31. Tyo, E. C. \& Vajda, S. Catalysis by clusters with precise numbers of atoms. Nat. Nanotechnol. 10, 577-588 (2015).

32. Liu, L. et al. Structural modulation and direct measurement of subnanometric bimetallic PtSn clusters confined in zeolites. Nat. Catal. 3, 628-638 (2020).

33. Craciun, V. \& Singh, R. K. Characteristics of the surface layer of barium strontium titanate thin films deposited by laser ablation. Appl. Phys. Lett. 76 1932-1934 (2000).

34. Miot, C., Husson, E., Proust, C., Erre, R. \& Coutures, J. P. X-ray photoelectron spectroscopy characterization of barium titanate ceramics prepared by the citric route. Residual carbon study. J. Mater. Res. 12, 2388-2392 (2011).

35. Wang, S. et al. Light-switchable oxygen vacancies in ultrafine $\mathrm{Bi}_{5} \mathrm{O}_{7} \mathrm{Br}$ nanotubes for boosting solar-driven nitrogen fixation in pure water. $A d v$. Mater. 29, 1701774 (2017).

36. Ricci, D., Bano, G., Pacchioni, G. \& Illas, F. Electronic structure of a neutral oxygen vacancy in $\mathrm{SrTiO}_{3}$. Pyhs. Rev. B 68, 224105 (2003).

37. Qi, Y. et al. Photoinduced defect engineering: enhanced photothermal catalytic performance of $2 \mathrm{D}$ black $\operatorname{In}_{2} \mathrm{O}_{3-\mathrm{x}}$ nanosheets with bifunctional oxygen vacancies. Adv. Mater. 32, 1903915 (2020).

38. Li, J. et al. The spatially oriented charge flow and photocatalysis mechanism on internal van der Waals heterostructures enhanced g- $\mathrm{C}_{3} \mathrm{~N}_{4}$. ACS Catal. 8, 8376-8385 (2018).

39. Hadjiivanov, K. \& Knözinger, H. Species formed after NO adsorption and $\mathrm{NO}+\mathrm{O}_{2}$ co-adsorption on $\mathrm{TiO}_{2}$ : an FTIR spectroscopic study. Phys. Chem. Chem. Phys. 2, 2803-2806 (2000).

40. Kantcheva, M. Identification, stability, and reactivity of NOx species adsorbed on titania-supported manganese catalysts. J. Catal. 204, 479-494 (2001).

41. Hadjiivanov, K., Avreyska, V., Klissurski, D. \& Marinova, T. Surface species formed after $\mathrm{NO}$ adsorption and $\mathrm{NO}+\mathrm{O}_{2}$ coadsorption on $\mathrm{ZrO}_{2}$ and sulfated $\mathrm{ZrO}_{2}$ : an FTIR spectroscopic study. Langmuir 18, 1619-1625 (2012).

42. Li, P. et al. Visible light-driven nitrogen fixation catalyzed by $\mathrm{Bi}_{5} \mathrm{O}_{7} \mathrm{Br}$ nanostructures: enhanced performance by oxygen vacancies. J. Am. Chem. Soc. 142, 12430-12439 (2020).

43. Li, H., Shang, J., Ai, Z. \& Zhang, L. Efficient visible light nitrogen fixation with $\mathrm{BiOBr}$ nanosheets of oxygen vacancies on the exposed $\{001\}$ facets. J. Am. Chem. Soc. 137, 6393-6399 (2015).

44. Zhao, Y. et al. Layered-double-hydroxide nanosheets as efficient visible-lightdriven photocatalysts for dinitrogen fixation. Adv. Mater. 29, 1703828 (2017).

45. Pigos, J. M., Brooks, C. J., Jacobs, G. \& Davis, B. H. Low temperature water-gas shift: characterization of Pt-based $\mathrm{ZrO} 2$ catalyst promoted with $\mathrm{Na}$ discovered by combinatorial methods. Appl. Catal. A: Gen. 319, 47-57 (2007).

46. Lukaski, A. Photocatalytic oxidation of methyl formate on $\mathrm{TiO}_{2}$ : a transient DRIFTS study. J. Catal. 223, 250-261 (2004).

47. Gao, H. \& Yan, T. DFT and DRIFTS study on the vibrational spectra of formate species adsorbed on the $\mathrm{Cu}-\mathrm{Al}_{2} \mathrm{O}_{3}$ catalyst. J. Mol. Struct. 889, 191-196 (2008).

48. Corral-Pérez, J. J., Copéret, C. \& Urakawa, A. Lewis acidic supports promote the selective hydrogenation of carbon dioxide to methyl formate in the presence of methanol over Ag catalysts. J. Catal. 380, 153-160 (2019).

49. Wan, J. et al. Defect effects on $\mathrm{TiO}_{2}$ nanosheets: stabilizing single atomic site au and promoting catalytic properties. Adv. Mater. 30, 1705369 (2018).

50. Liu, G. et al. Visible light responsive nitrogen doped anatase $\mathrm{TiO}_{2}$ sheets with dominant $\{001\}$ facets derived from TiN. J. Am. Chem. Soc. 131, 12868-12869 (2009). 
51. Kresse, G. \& Furthmüller, J. Efficient iterative schemes for ab initio totalenergy calculations using a plane-wave basis set. Phys. Rev. B 54, 11169-11186 (1996).

52. Perdew, J. P., Burke, K. \& Ernzerhof, M. Generalized gradient approximation made simple. Phys. Rev. Lett. 77, 3865-3868 (1996).

53. Kresse, G. \& Furthmüller, J. Efficiency of ab-initio total energy calculations for metals and semiconductors using a plane-wave basis set. Comp. Mater. Sci. 6, 15-50 (1996).

54. Dudarev, S. L., Botton, G. A., Savrasov, S. Y., Humphreys, C. J. \& Sutton, A. P. Electron-energy-loss spectra and the structural stability of nickel oxide. Phys. Rev. B: Condens. Matter Mater. Phys. 57, 1505-1509 (1998).

55. Zuluaga, S. \& Stolbov, S. Factors controlling the energetics of the oxygen reduction reaction on the Pd-Co electro-catalysts: insight from first principles. J. Chem. Phys. 135, 134702 (2011).

56. Norskov, J. K. et al. Origin of the overpotential for oxygen reduction at a fuelcell cathode. J. Phys. Chem. B 108, 17886-17892 (2004).

57. Henkelman, G. A climbing image nudged elastic band method for finding saddle points and minimum energy paths. J. Chem. Phys. 113, 9901-9904 (2000).

58. Henkelman, G. \& Jónsson, H. Improved tangent estimate in the nudged elastic band method for finding minimum energy paths and saddle points. J. Chem. Phys. 113, 9978-9985 (2000).

59. Ren, H. T., Jia, S. Y., Zou, J. J., Wu, S. H. \& Han, X. A facile preparation of $\mathrm{Ag}_{2} \mathrm{O} / \mathrm{P} 25$ photocatalyst for selective reductionof nitrate. Appl. Catal. B: Environ. 176-177, 53-61 (2015).

60. Anderson, J. A. Simultaneous photocatalytic degradation of nitrate and oxalic acid over gold promoted titania. Catal. Today 181, 171-176 (2012).

61. Tong, N. et al. $\mathrm{PdSn} / \mathrm{NiO} / \mathrm{NaTaO}_{3}: \mathrm{La}$ for photocatalytic ammonia synthesis by reduction of $\mathrm{NO}_{3}{ }^{-}$with formic acid in aqueous solution. J. Catal. 361, 303-312 (2018).

62. Luo, Y. R. et al. Efficient electrocatalytic $\mathrm{N}_{2}$ fixation with MXene under ambient conditions. Joule 3, 279-289 (2019).

63. $\mathrm{Wu}, \mathrm{T}$. et al. Identifying the origin of $\mathrm{Ti}^{(3+)}$ activity toward enhanced electrocatalytic $\mathrm{N}_{2}$ reduction over $\mathrm{TiO}_{2}$ nanoparticles modulated by mixedvalent copper. Adv. Mater. 32, 2000299 (2020).

64. Han, L. L. et al. Modulating single-atom palladium sites with copper for enhanced ambient ammonia electrosynthesis. Angew. Chem. Int. Ed. 60, 345-350 (2021).

65. Ghorai, U. K. et al. Scalable production of cobalt phthalocyanine nanotubes: efficient and robust hollow electrocatalyst for ammonia synthesis at room temperature. ACS Nano 15, 5230-5239 (2021).

66. Sim, H. Y. F. et al. ZIF-induced d-band modification in a bimetallic nanocatalyst: achieving over $44 \%$ efficiency in the ambient nitrogen reduction reaction. Angew. Chem. Int. Ed. 59, 16997-17003 (2020).

67. Su, H. Y. et al. Single atoms of iron on $\mathrm{MoS}_{2}$ nanosheets for $\mathrm{N}_{2}$ electroreduction into ammonia. Angew. Chem. Int. Ed. 59, 20411-20416 (2020).

68. $\mathrm{Bi}, \mathrm{K}$. et al. Charge carrier dynamics investigation of $\mathrm{Cu}_{2} \mathrm{~S}-\mathrm{In}_{2} \mathrm{~S}_{3}$ heterostructures for the conversion of dinitrogen to ammonia via photoelectrocatalytic reduction. J. mater. Chem. A 9, 10497-10507 (2021).

69. Liu, D. et al. Photoelectrochemical synthesis of ammonia with black phosphorus. Adv. Funct. Mater. 30, 2002731 (2020).

70. Zheng, J. et al. Photoelectrochemical synthesis of ammonia on the aerophilichydrophilic heterostructure with $37.8 \%$ efficiency. Chem 5, 617-633 (2019).

71. Chen, C. et al. Coupling $\mathrm{N}_{2}$ and $\mathrm{CO}_{2}$ in $\mathrm{H}_{2} \mathrm{O}$ to synthesize urea under ambient conditions. Nat. Chem. 12, 717-724 (2020)

72. Tao, H. et al. Nitrogen fixation by Ru single-atom electrocatalytic reduction. Chem 5, 204-214 (2019).
73. Wang, W. et al. Potassium-ion-assisted regeneration of active cyano groups in carbon nitride nanoribbons: visible-light-driven photocatalytic nitrogen reduction. Angew. Chem. Int Ed. Engl. 58, 16644-16650 (2019).

74. Shang, S. et al. Atomically dispersed iron metal site in a porphyrin-based metal-organic framework for photocatalytic nitrogen fixation. ACS Nano 15 9670-9678 (2021).

75. Chen, L. W. et al. Metal-organic framework membranes encapsulating gold nanoparticles for direct plasmonic photocatalytic nitrogen fixation. J. Am. Chem. Soc. 143, 5727-5736 (2021).

\section{Acknowledgements}

This work was supported by the National key R\&D project of China (Grant No. 2020YFA0710000), National Natural Science Foundation of China (Grant Nos. 21822601, 22176029, and 22006009), Excellent Youth Foundation of Sichuan Scientific Committee Grant in China (No. 2021JDJQ0006), the Fundamental Research Funds for the Central Universities (ZYGX2019Z021) and the 111 Project (B20030).

\section{Author contributions}

J.Y.L and F.D. conceived and designed the experiments. J.Y.L., R.M.C., and J.L.W carried out the materials fabrication, performance tests, characterizations, and calculations. Y.Z. and G.D.Y. helped analyzed the experimental data. J.Y.L. and F.D. wrote the paper, and all authors discussed the results and commented on the manuscript.

\section{Competing interests}

The authors declare no competing interests.

\section{Additional information}

Supplementary information The online version contains supplementary material available at https://doi.org/10.1038/s41467-022-28740-8.

Correspondence and requests for materials should be addressed to Fan Dong.

Peer review information Nature Communications thanks Bing-Jie $\mathrm{Ni}, \mathrm{X}$ and the other anonymous reviewer(s) for their contribution to the peer review of this work. Peer reviewer reports are available.

Reprints and permission information is available at http://www.nature.com/reprints

Publisher's note Springer Nature remains neutral with regard to jurisdictional claims in published maps and institutional affiliations.

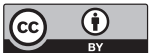

Open Access This article is licensed under a Creative Commons Attribution 4.0 International License, which permits use, sharing, adaptation, distribution and reproduction in any medium or format, as long as you give appropriate credit to the original author(s) and the source, provide a link to the Creative Commons license, and indicate if changes were made. The images or other third party material in this article are included in the article's Creative Commons license, unless indicated otherwise in a credit line to the material. If material is not included in the article's Creative Commons license and your intended use is not permitted by statutory regulation or exceeds the permitted use, you will need to obtain permission directly from the copyright holder. To view a copy of this license, visit http://creativecommons.org/ licenses/by/4.0/.

(C) The Author(s) 2022 